\title{
Neurofilament light: a possible prognostic biomarker for treatment of vascular contributions to cognitive impairment and dementia
}

Christina Hoyer-Kimura ${ }^{1 *} \mathbb{1}$, John P. Konhilas ${ }^{1,2,3,4}$, Heidi M. Mansour ${ }^{5,6}$, Robin Polt ${ }^{7}$, Kristian P. Doyle $^{8}$, Dean Billheimer ${ }^{11}$ and Meredith Hay ${ }^{1,9,10,12}$

\begin{abstract}
Background: Decreased cerebral blood flow and systemic inflammation during heart failure (HF) increase the risk for vascular contributions to cognitive impairment and dementia (VCID) and Alzheimer disease-related dementias (ADRD). We previously demonstrated that PNA5, a novel glycosylated angiotensin 1-7 (Ang-(1-7)) Mas receptor (MasR) agonist peptide, is an effective therapy to rescue cognitive impairment in our preclinical model of VCID. Neurofilament light (NfL) protein concentration is correlated with cognitive impairment and elevated in neurodegenerative diseases, hypoxic brain injury, and cardiac disease. The goal of the present study was to determine (1) if treatment with Ang-(1-7)/MasR agonists can rescue cognitive impairment and decrease VCID-induced increases in NfL levels as compared to HF-saline treated mice and, (2) if NfL levels correlate with measures of cognitive function and brain cytokines in our VCID model.
\end{abstract}

Methods: VCID was induced in C57BL/6 male mice via myocardial infarction (MI). At 5 weeks post-MI, mice were treated with daily subcutaneous injections for 24 days, 5 weeks after Ml, with PNA5 or angiotensin 1-7 (500 microg/ $\mathrm{kg} / \mathrm{day}$ or $50 \mathrm{microg} / \mathrm{kg} / \mathrm{day}$ ) or saline ( $n=15 / \mathrm{group}$ ). Following the 24 -day treatment protocol, cognitive function was assessed using the Novel Object Recognition (NOR) test. Cardiac function was measured by echocardiography and plasma concentrations of NfL were quantified using a Quanterix Simoa assay. Brain and circulating cytokine levels were determined with a MILLIPLEX MAP Mouse High Sensitivity Multiplex Immunoassay. Treatment groups were compared via ANOVA, significance was set at $p<0.05$.

Results: Treatment with Ang-(1-7)/MasR agonists reversed VCID-induced cognitive impairment and significantly decreased NfL levels in our mouse model of VCID as compared to HF-saline treated mice. Further, NfL levels were significantly negatively correlated with cognitive scores and the concentrations of multiple pleiotropic cytokines in the brain.

Conclusions: These data show that treatment with Ang-(1-7)/MasR agonists rescues cognitive impairment and decreases plasma NfL relative to HF-saline-treated animals in our VCID mouse model. Further, levels of NfL are significantly negatively correlated with cognitive function and with several brain cytokine concentrations. Based on these

\footnotetext{
*Correspondence: choyerkimura@email.arizona.edu

${ }^{1}$ Department of Physiology, The University of Arizona, Tucson, AZ, USA

Full list of author information is available at the end of the article
} original author(s) and the source, provide a link to the Creative Commons licence, and indicate if changes were made. The images or other third party material in this article are included in the article's Creative Commons licence, unless indicated otherwise in a credit line to the material. If material is not included in the article's Creative Commons licence and your intended use is not permitted by statutory regulation or exceeds the permitted use, you will need to obtain permission directly from the copyright holder. To view a copy of this licence, visit http://creativecommons.org/licenses/by/4.0/. The Creative Commons Public Domain Dedication waiver (http://creativeco mmons.org/publicdomain/zero/1.0/) applies to the data made available in this article, unless otherwise stated in a credit line to the data. 
preclinical findings, we propose that circulating NfL might be a candidate for a prognostic biomarker for VCID and may also serve as a pharmacodynamic/response biomarker for therapeutic target engagement.

Keywords: Neurofilament light (NfL), Biomarker, Vascular contributions to cognitive impairment and dementia, Inflammation, PNA5, Angiotensin-(1-7)

\section{Introduction}

Increases in brain and systemic inflammation, and decreased brain blood flow, as seen during heart failure (HF) [1], are strongly correlated with the development of vascular contributions to cognitive impairment and dementia (VCID) and Alzheimer's disease-related dementias (ADRD) [2,3]. With an aging population and a strong link between cardiovascular and cerebrovascular disease and subsequent cognitive impairment and dementia, there is a growing need for safe and effective therapies to protect cognitive function in individuals at risk for VCID [4].

Angiotensin 1-7 (Ang-(1-7)) is a clinically safe peptide [5] that decreases inflammation and increases cerebral blood flow in our VCID preclinical model [6-8]. Through targeting Mas receptors (MasR), located on neurons, microglia, and vascular endothelial cells in the brain [9], Ang-(1-7) decreases brain inflammation and increases cerebral circulation [9]. MasRs that regulate vasodilation are highly expressed in the hippocampus and perirhinal cortex, which makes them an ideal target for treating brain disease related to hypoxia and inflammation that impair memory, such as VCID and ADRD [6, 7]. Our collaborative team has developed and optimized a novel, synthetic Ang-(1-7)-derived glycopeptide, PNA5, that selectively activates MasR and has improved bioavailability and brain penetration compared to the native Ang-(1-7) peptide. We have previously shown that PNA5 targets MasR, reverses cognitive impairment in our preclinical VCID model, and inhibits circulating and brain inflammatory cytokine production [7].

Neurofilament light protein (NfL) is an intermediate filament protein that is a component of the cytoskeleton of neurons and is abundantly expressed in axons $[10,11]$. NfL levels are increased in the brain following axonal damage and neurodegeneration $[10,11]$ and increases in serum NfL correlate with cerebrospinal fluid (CSF) levels and increased cognitive impairment [12]. NfL has been found to be elevated in subjects suffering from multiple sclerosis $[12,13]$, as well as traumatic brain injury [14, 15], hypoxic brain injury [16], and cardiac disease and related surgeries [17].

In the present study, we hypothesized that (1) treatment with Ang-(1-7)/MasR agonists will rescue cognitive impairment and decrease VCID-induced NfL levels as compared to HF-saline treated mice, and (2) NfL levels will correlate with measures of both cognitive function and VCID-induced increases in brain cytokines. Our results indicate that circulating NfL might serve as a possible prognostic biomarker of cognitive impairment in VCID. Further, NfL might be a candidate biomarker to identify target engagement following treatment with Ang-(1-7)/MasR agonists in VCID.

\section{Methods}

\section{Animal}

Three-month-old ( $25-30$ g) C57BL/6 male mice (Jackson Laboratories, Bar Harbor, Maine) were ordered and housed 3 per cage in a temperature and humidity-controlled facility on a $12 \mathrm{~h}$ light/dark cycle. Mice are acclimated upon receival for a week before undergoing MI. Water and chow were available ab libitum for the duration of the experiments. Experiments were performed with adherence to guidelines approved by the Institutional Animal Care and Use Committee at the University of Arizona and in accordance with the National Institutes of Health Guidelines for the Care and Use of Laboratory Animals. The number of animals needed per experimental group was determined using a G*Power analysis.

\section{VCID animal model}

Mice were weighed prior to surgery and anesthetized with $2.5 \%$ isoflurane in a mixture of air and $\mathrm{O}_{2}$. Left coronary artery (LCA) ligation was used to induce myocardial infarction (MI) using the procedure described in Gao et al. [18]. In short, a left-sided thoracotomy was performed at the fourth intercostal space and the LCA was sutured to induce a permanent ligation and MI. Occlusion of the LCA was confirmed by observing myocardial blanching of the left ventricular anterior wall. Control mice underwent sham surgeries, undergoing the same procedure except for the permanent LCA ligation.

\section{Experimental protocol}

Mice were assigned randomly to the following treatment groups: Control-Saline (sham MI surgery, treated with saline), HF-treated (HF-PNA5, or HF-Ang-(1-7) with either $50 \mu \mathrm{g} / \mathrm{kg} /$ day, or $500 \mu \mathrm{g} / \mathrm{kg} /$ day), or HFsaline. Mice recovered for 5 weeks following MI before receiving 24 days of daily subcutaneous drug treatment. Within the last 3 days of injections, animals underwent Novel Object Recognition (NOR) testing (Fig. 1). 


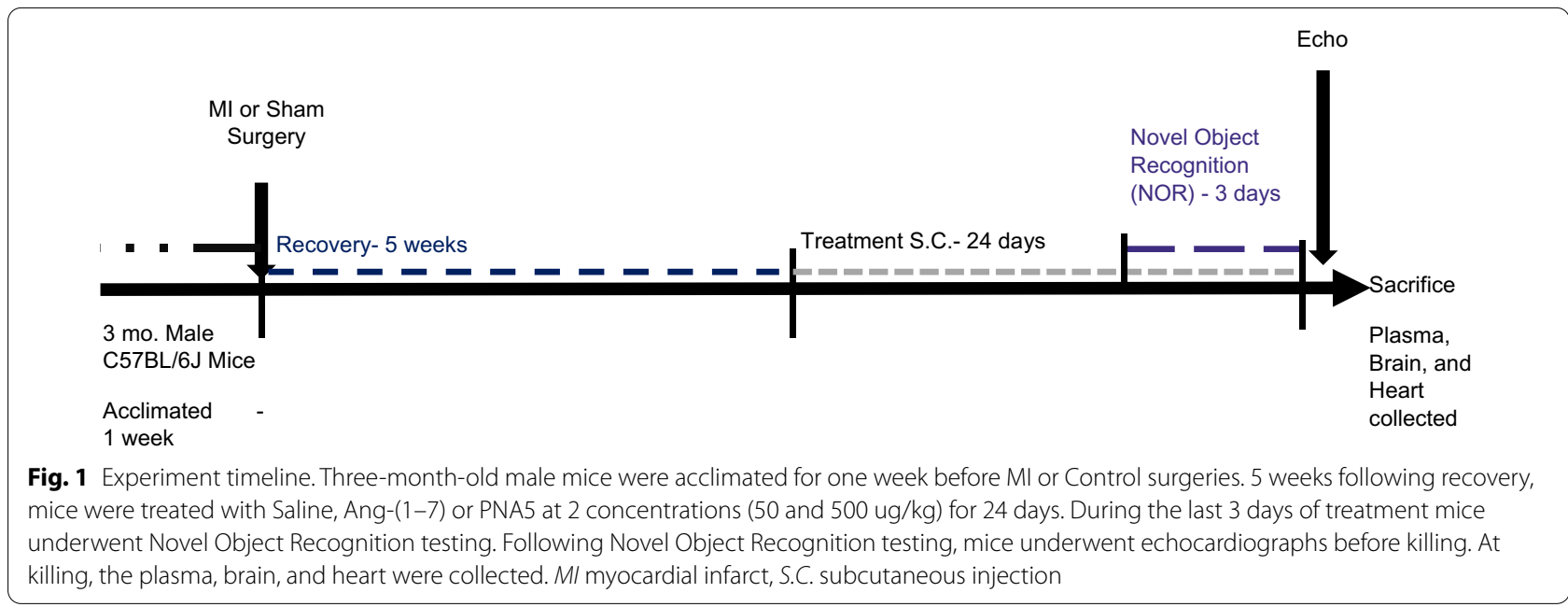

Animal treatment groups were as listed: heart failure (HF)-saline treated $n=15$, (HF-Saline), Sham surgerysaline treated $\mathrm{n}=15$ (Control-Saline), HF-Ang-(1-7) at $500 \mu \mathrm{g} /$ kilogram body weight/ day for 24 days (HFA500) $n=15$, HF-Ang-(1-7) at $50 \mu \mathrm{g} / \mathrm{kg}$ body weight/ day for 24 days (HF-A50) $n=15$, HF-PNA5 at $500 \mu \mathrm{g} /$ kilogram body weight / day (HF-P500) $n=15$, HFPNA5 at $50 \mu \mathrm{g} /$ kilogram body weight/day (HF-P50) $\mathrm{n}=15$. Following MI, up to 7 mice died within a group resulting in varying number of mice per group that were available to undergo treatment, NOR testing, and provide serum samples.

\section{Echocardiography}

Transthoracic, high-resolution ultrasound was performed the day of, or up to 2 days prior to, tissue harvesting using a Vevo 2100 High-Resolution Imaging System (Visual Sonics, Toronto, ON, Canada) and a $25-\mathrm{MHz}$ transducer. Mouse chest hair was removed using a chemical depilatory. Echocardiographs were performed on anesthetized mice under $2 \%$ isoflurane and an $\mathrm{O}_{2} /$ air mixture. Echocardiographic images were taken in $\mathrm{B}$ mode from the parasternal angle both on long and short-axis view at three levels starting at the apex, mid-ventricle, and top of the ventricle. The thickness of the left ventricular wall, cardiac chamber dimensions, interventricular septum, left ventricular posterior wall thickness, and left ventricular internal dimension were measured using Vevo $2100^{\circledR}$ analytic software (Visual Sonics, Toronto, ON, Canada). Only MI animals showing evidence of a significant MI, defined by significant wall motion abnormalities, and reduced contractile function, were included in the study.

\section{Preparation of Ang-(1-7) and the glycosylated Ang1-7, PNA5 peptides}

To prepare the injections, solid peptides were dissolved in double distilled water and stored in a $-20^{\circ} \mathrm{C}$ freezer in aliquots of $1.5 \mathrm{~mL}$ at a stock concentration of $1 \mathrm{mg} /$ $\mathrm{mL}$. The stock drugs were diluted daily in sterile saline to make the following treatment concentrations: A50 $50 \mu \mathrm{g} / \mathrm{kg}$ (1.5 mg Ang-(1-7) /300 mL saline), P50 $50 \mu \mathrm{g} /$ $\mathrm{kg}(1.5 \mathrm{mg}$ PNA $5 / 300 \mathrm{~mL}$ saline), A500 $500 \mu \mathrm{g} / \mathrm{kg}(15 \mathrm{mg}$ Ang-(1-7)/300 mL saline), P500 $500 \mu \mathrm{g} / \mathrm{kg}$ (15 mg PNA5/300 mL saline). Treatments were stored in a $4{ }^{\circ} \mathrm{C}$ refrigerator in prefilled syringes (peptide solutions are stable up to 28 days when stored at $4{ }^{\circ} \mathrm{C}$ ).

\section{Subcutaneous injections}

Daily treatment was delivered subcutaneously either at the scruff or inguinal area for 24 days using a 15-gauge needle. All prepared drugs were kept in the $4{ }^{\circ} \mathrm{C}$ refrigerator before use and transported on ice before injection. All procedures were performed within the housing facility to minimize stress.

\section{Novel Object Recognition (NOR) test}

Mouse cognition was evaluated using the Novel Object Recognition test. For this test, the arena was an evenly illuminated chamber $(12 \times 12 \times 12 \mathrm{~cm})$ placed in a light and sound-controlled room. The walls of the arena were white, and the floor had a grid to ensure that the placement of the objects remained the same between phases of the test. Exploratory behavior was measured using a digital camera and evaluated by calculating the time spent exploring each object. Orientation of the nose toward an object at a distance of $\sim 2 \mathrm{~cm}$ or less was considered exploratory behavior [19]. Other behaviors including 
rearing on the object and resting against the object were not considered exploratory. Importantly, we have demonstrated that exploration is similar in both Control-Saline and HF-Saline treated mice, indicating that MI does not have a significant impact on mouse movement after 8 weeks of HF [6, 7]. Individuals scoring mouse exploration were blinded to treatment group. Three sets of distinct objects were used, variable in size, color, and shape, and made of either plastic, glass, or wood.

For the habituation phase of the test, mice were habituated to an empty testing arena for $10 \mathrm{~min}$ each day for 2 days. For the learning phase of the test, two identical objects were placed in the testing arena and the mouse was allowed to explore the objects for $6 \mathrm{~min}$. After the $6 \mathrm{~min}$ of exploration, mice were returned to their home cage for $2 \mathrm{~h}$. For the memory testing phase, one of the objects was replaced with a novel object and the mice were returned to the testing arena and allowed to explore the objects for $2 \mathrm{~min}$. In between each phase, the testing boxes were cleaned with 70\% ETOH to prevent the influence of olfactory cues. Analysis: Recognition memory was scored using a discriminatory ratio (discrimination ratio) calculated by: discrimination ratio = the time spent exploring the novel object $\left(t_{\text {novel }}\right)$ minus the time spent exploring the familiar object $\left(\mathrm{t}_{\text {familiar }}\right)$ divided by the total exploration time: were then rapidly frozen in corning tubes in liquid nitrogen and stored at $-80^{\circ} \mathrm{C}$. One half of each brain was lysed using $1 \mathrm{~mL}$ RIPA buffer (1\% Triton X-100, 0.1\% SDS, $1 \times$ PBS) with protease (protease inhibitor cocktail 100x [Sigma P8340]) and phosphatase inhibitors (phosphatase inhibitor cocktail 100x [Sigma P5726]). Tissue was then sonicated using an ultrasonic cell disruptor at 30\% 40\% amplitude for $1 \mathrm{~min}$. Samples were returned to ice in between sonication to prevent the tissue from warming. Samples were then centrifuged at $4{ }^{\circ} \mathrm{C}$ or $15 \mathrm{~min}$ at $13,000 \times g$. The supernatant was collected and stored at $-80{ }^{\circ} \mathrm{C}$. Total protein was measured in the range of $5-10 \mathrm{mg} / \mathrm{mL}$. Brain lysates were used for multiplex immunoassays.

\section{Cytokine measurement}

Cytokine concentrations were measured in the brain lysates and plasma samples by multiplex immunoassay using a MAGPIX Multiplexing Instrument and accompanying Multiplex Analyst software (MILLIPLEX MAP Mouse Cytokine/Chemokine Magnetic Bead PanelImmunology Multiplex Assay; MCYTOMAG-70 K; Millipore Sigma, Burlington, Massachusetts). Simultaneous measurements of granulocyte colony-stimulating factor (GCSF), granulocyte-macrophage colony-stimulating factor, interferon, interleukin (IL)-1a,

Discrimination ratio $=\left(t_{\text {novel }}-t_{\text {familiar }}\right) /($ total exploration time $)$.

A positive discrimination ratio score indicates that the mouse spent more time at the novel object than the familiar object, while a negative score indicates that the mouse spent more time with the familiar object than the novel object. A zero discrimination ratio score indicates a null preference. Typically, in healthy states, mice will spend a greater amount of time with the novel object than the familiar object. Discrimination ratios between groups were analyzed using ANOVA, followed by Dunnett's post with significance set at $p<0.05$.

\section{Measurement of neurofilament light (NfL)}

Upon killing, blood was collected via heparinized syringe from the neck following decapitation. Collected blood was centrifuged and the plasma stored at $-80^{\circ} \mathrm{C}$ before shipment to PBL Assay Science for measurement of NfL using a Quanterix-Simoa assay (NF-LIGHT ${ }^{\circledR}$ 103186, PBL, Neurofilament-Light Advantage Assay Kit).

\section{Brain lysis}

Mice were anesthetized with isoflurane and rapidly decapitated. Brains were separated from the skull and quickly cut into two hemispheres. The halves of the brain
IL-1B, IL-2, IL-4, IL-5, IL-6, IL-7, IL-9, IL-10, IL-12 (p40), IL-12(p70), IL-13, IL-15, IL-17, interferon-induced protein 10 , chemokine (C-X-C motif) (CXC) ligand $1(\mathrm{KC})$, chemokine (C-C motif) ligand(CCL) 2 (monocyte chemoattractant protein-1), CCL3 [macrophage inflammatory protein (MIP) 1a], CCL4 (MIP1b), CXC ligand 2 (MIP2),CCL5 [RANTES (regulated on activation normal $T$ cell expressed and secreted)], and tumor necrosis factor-alpha (TNF- $\alpha)$ were captured. All samples were run in duplicate, and the results were analyzed using ANOVA and relevant post using GraphPad Prism9. To create a composite cytokine score, we calculated the $z$-scores for IL-2, IL-13, and IL-17 brain cytokines. Z-scores were then added to create a composite cytokine score. The $z$-score was calculated for each cytokine using the following equation:

$$
\mathrm{z} \text { score }=(\text { individual value }- \text { mean value }) / \mathrm{SD} \text {. }
$$

\section{Heart tissue fixation}

Mice were anesthetized with isoflurane and rapidly decapitated. The heart was exposed by opening the chest cavity and excised. The heart, while still beating, was then 
A

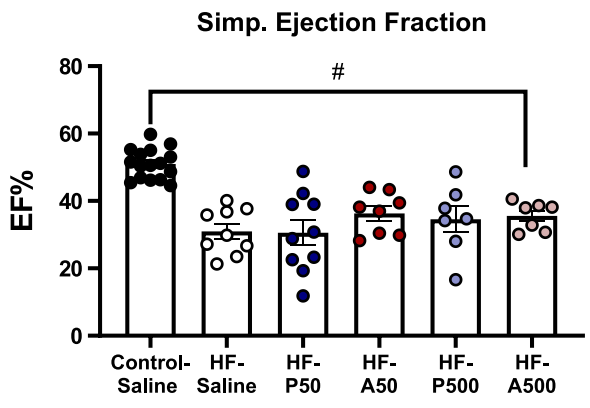

$\# p<0.05$ Control-Saline vs all treatment groups
B

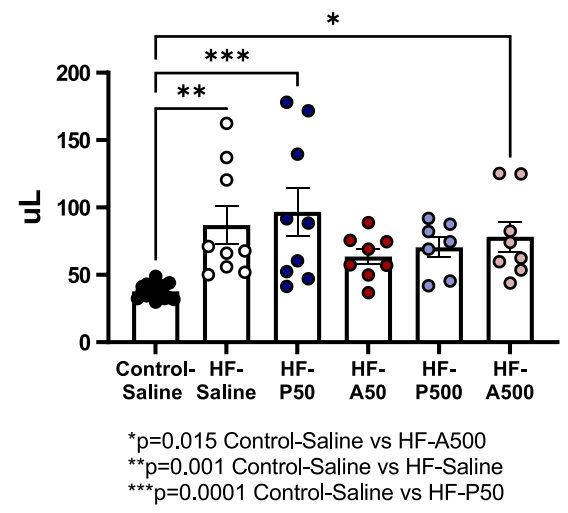

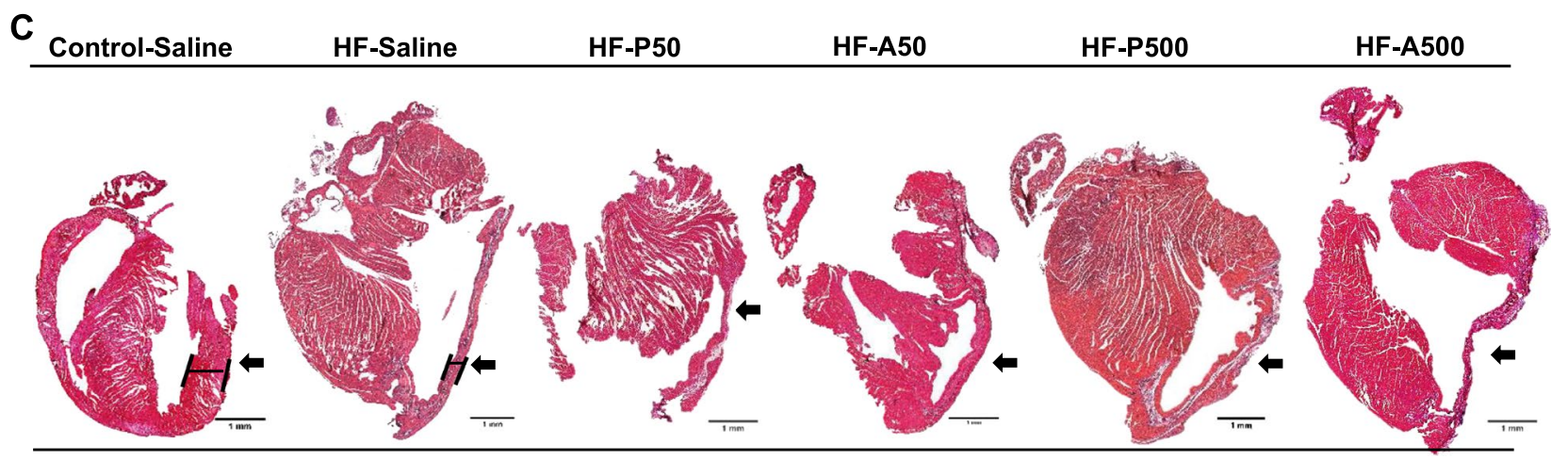

5X

Fig. 2 Echocardiograms and histology to confirm myocardial infarctions in the heart failure model. A Simpson Ejection Fraction was calculated using V-mode left ventricle calculations treatment groups: heart failure (HF)-A50 (Ang-(1-7)50 ug/kg), HF-P50 (PNA5 50ug/kg), HF-A500 (Ang-(1-7) $500 \mathrm{ug} / \mathrm{kg}$ ), HF-P500 (PNA5 500 ug/kg), HF-Saline, Control-Saline. Significant difference between Control-Saline and the following treatment groups are as listed: HF-Saline, HF-A50 (Ang-(1-7)50 ug/kg), HF-P50 (PNA5 50 ug/kg), HF-A500 (Ang-(1-7)500 ug/kg), HF-P500 (PNA5 500 ug/ $\mathrm{kg}), P<0.05$ ANOVA, Dunnett's post. B Simpson End Systolic Volume was calculated using V-mode left ventricle calculation. Significant difference between Control-Saline and the following treatment groups are as listed: HF-Saline $p=0.001$, HF-P50 (PNA5 50 ug/kg) $p=0.0001$, and HF-A500 (Ang-(1-7)500 ug/kg) $p=0.015$, ANOVA, Dunnett's post. C Examples of hematoxylin and eosin staining of paraffin embedded formalin fixed hearts demonstrates differences in wall morphology between Control animals and HF-saline, PNA5, and Ang-(1-7) treatment mice. Left ventricle wall is indicated with black arrow. Images were taken at $5 \times$ magnification

washed in ice cold PBS, dried, and weighed. Hearts were then cut longitudinally, exposing the interventricular septum and both ventricle chambers, and immersed in $10 \%$ formalin overnight at $4{ }^{\circ} \mathrm{C}$. Hearts were then dehydrated in methanol with at least two methanol changes before being cleared with xylene for $45 \mathrm{~min}$. Hearts were then wax permeabilized and paraffin embedded.

\section{Histochemistry}

Paraffin-embedded hearts were sectioned on a microtome to a thickness of 5-microns and mounted onto polarized slides. They were then stained with hematoxylin and eosin to visualize heart morphology and cellular infiltrates.

\section{Statistical analysis}

Data were analyzed using GraphPad Prism 9.0. Values are expressed as mean \pm SE. The Shapiro-Wilk $W$-test was used for determining normal distribution of the data. Differences between multiple groups were analyzed with ANOVA followed by appropriate post hoc group comparisons where indicated. Comparison of NfL levels between the Control-Saline and HF-Saline groups were analyzed with an unpaired t-test. Statistical significance was set at $p$ value $<0.05$. Association between NfL levels and discrimination ratio scores and the brain cytokines were analyzed using Pearson correlation. Statistical significance was set at $p$ value $<0.05$. The discrimination ratio vs NfL linear regression and brain cytokine vs NfL linear regression was used to generate a best-fit line. 


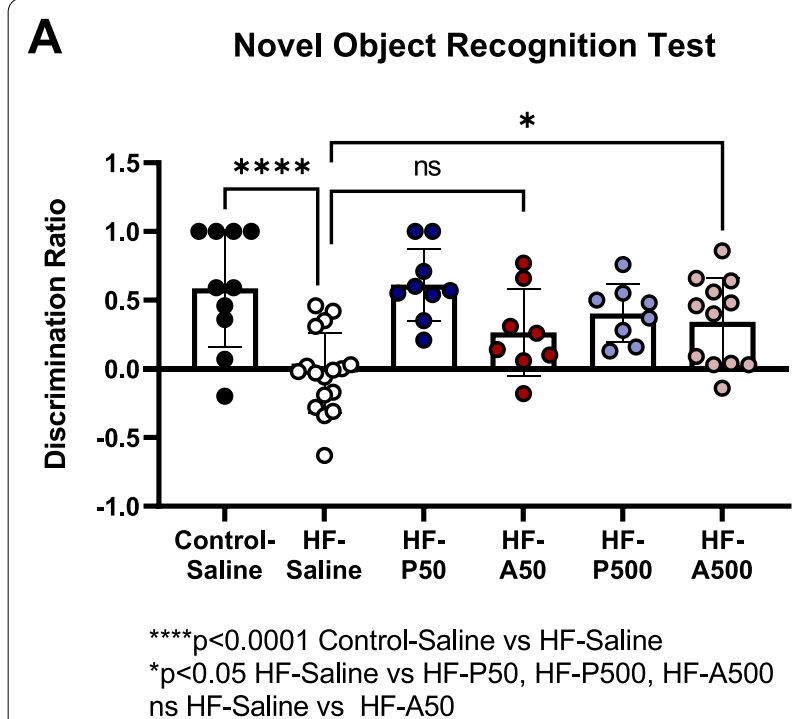

B

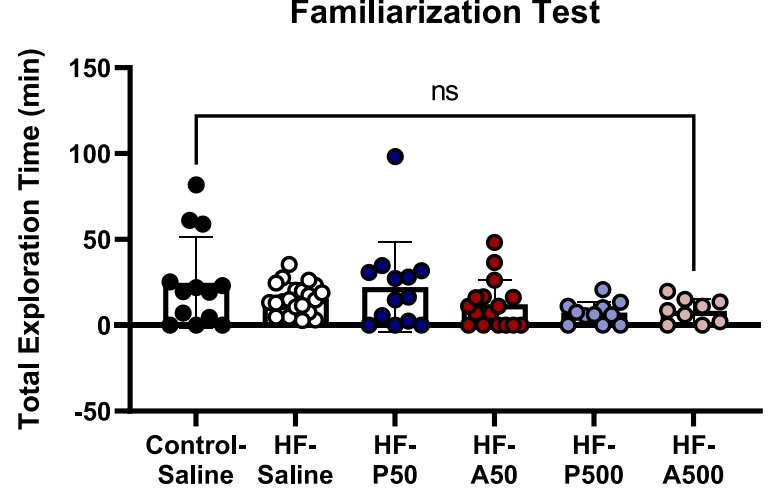

ns HF-Saline vs all other groups

Fig. 3 Ang-(1-7)/MasR agonists rescue cognitive impairment in a VCID mice. A Discrimination ratio=(Time spent at new object- Time spent at familiar object)/ total exploration time. Heart failure (HF) mice were treated with saline PNA5 or Ang-(1-7) at two different concentrations of either $50 \mathrm{ug} / \mathrm{kg}$, (P50, A50) or 500ug/kg (P500, A500). ${ }^{* * *} p<0.001$ Control-Saline vs HF-Saline. ${ }^{*} p<0.05$ HF-Saline vs HF-P50, HF-P500, HF-A500. Data are represented with mean and \pm SE. Difference in groups were tested by ANOVA, Dunnett's post, significance $p<0.05$. B No significant differences are noted in total exploration time in the familiarization test for all treatment groups. Data are represented with mean and \pm SE. Significancy were tested by ANOVA

\section{Results}

HF in VCID model is confirmed through loss of ventricular function

Our previous studies demonstrated that there is a significant deficit in cardiac function by 4 weeks post-MI $[6,7]$. Accordingly, echocardiography was performed at 8 weeks post-MI using the Simpson's method, the most used approach in clinical practice. As illustrated in Fig. 2A, at 8 weeks post-MI, ejection fractions (EF) were decreased in HF-Saline and Ang-(1-7) and PNA5-treated mice compared to Control-Saline-treated mice (Control-Saline, mean 50.98, \pm SE $1.12 n=17$ vs HF-Saline, mean $30.99 \pm$ SE 2.26, $n=9$, HF-A500, mean $35.56 \pm$ SE 1.60, $\mathrm{n}=7$, HF-P500, 34.54 \pm SE 3.86, $\mathrm{n}=7$, HF-P50, mean, $30.57 \pm$ SE 3.66, $n=10$, HF-A50 36.30 \pm SE 2.18, $n=8$; respectively, $\mathrm{p} \leq 0.0002$ ANOVA, Dunnett's post). Further, at 8 week post-MI, end systolic volume (ESV) were significantly increased in all groups HF-Saline, as compared to Control-Saline treated mice (ControlSaline, mean $37.78 \pm$ SE $1.30 n=17$ vs HF-VCID, mean $86.97 \pm$ SE 13.90, $n=9, \quad p=0.0013$, HF-A500, mean 78.29 \pm SE 11.02, $n=8, p=0.0149$, HF-P50, 96.79 \pm SE 17.87, $n=9, \quad p=0.0001$; ANOVA, Dunnett's post) (Fig. 2B). As observed in dilated hearts, our VCID mouse model has a thinned left ventricular wall [20]. Figure $2 \mathrm{C}$ is an illustrative example of left ventricular wall thinning in HF-Saline, PNA5, and Ang-(1-7) treatment treated mice compared to Control-Saline treated mice (indicated by black arrow).

\section{Ang-(1-7)/MasR activation rescues cognitive impairment in VCID mice}

As illustrated in Fig. 3A, treatment with Ang-(1-7)/MasR agonists rescues cognitive impairment in our mouse model of VCID. Cognitive function was measured using the NOR test following 24 days of treatment with either 50 or $500 \mu \mathrm{g} / \mathrm{kg} /$ day of either Ang-(1-7) or PNA5. Cognitive function was quantified using the Discrimination ratio score, with a negative, or zero Discrimination ratio indicating impaired cognitive function. HF mice treated with saline had an average negative Discrimination ratio of $-0.026 \pm$ SE 0.07 that was significantly lower than Control-Saline treated mice (mean 0.590 \pm SE $0.13, p<0.001$, ANOVA, Dunnett's post). This indicates, as previously described, that in our model of VCID, HF results in a decrease in cognitive function $[6,7]$.

Compared to HF-Saline animals, both treatment with PNA5 and Ang-(1-7) rescued the cognitive function in the VCID model. VCID mice treated with PNA5 at 50 or $500 \mu \mathrm{g} / \mathrm{kg} /$ day resulted in a discrimination ratio of $0.61 \pm \mathrm{SE} 0.08, n=9$, and $0.40 \pm \mathrm{SE} 0.08, n=8$, respectively (HF-P50 $p<0.0001$, HF-P500, $p=0.01$; ANOVA, Dunnett's post). Likewise, treatment with Ang-(1-7) at $500 \mu \mathrm{g} / \mathrm{kg} /$ day also rescued HF-induced cognitive 

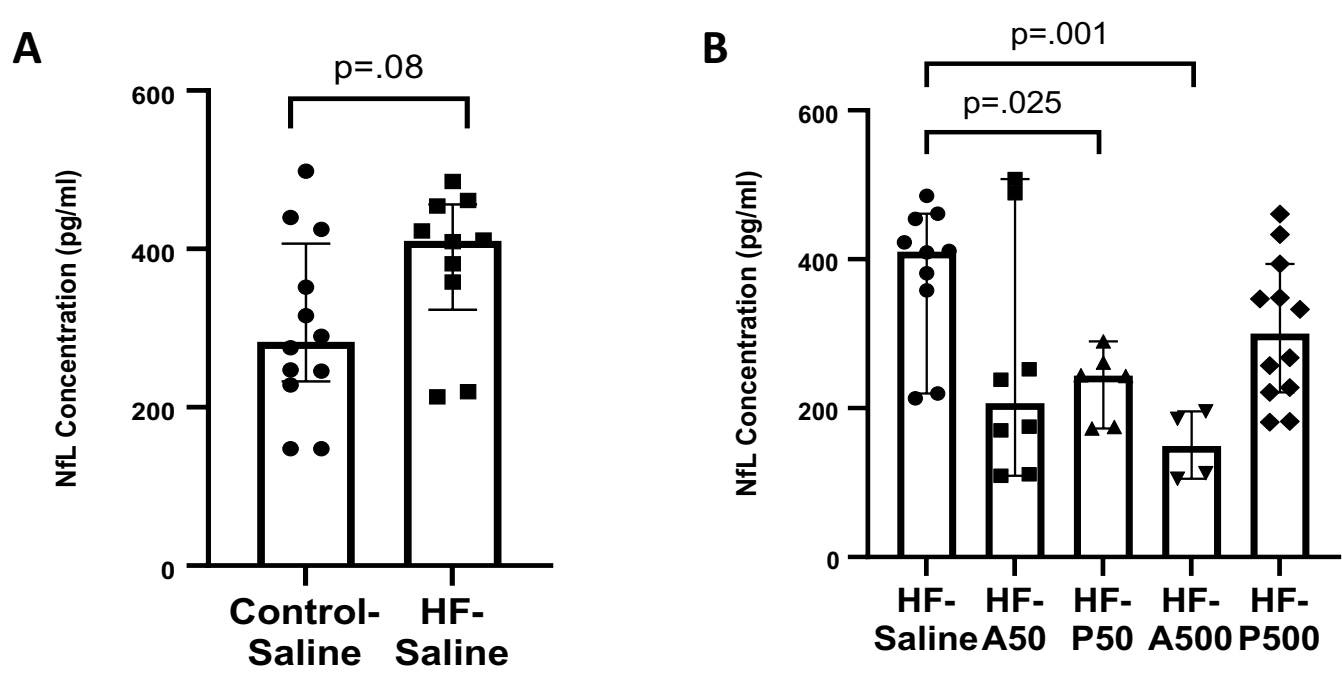

\section{C}

NFL vs. Discrimination Ratio Regression

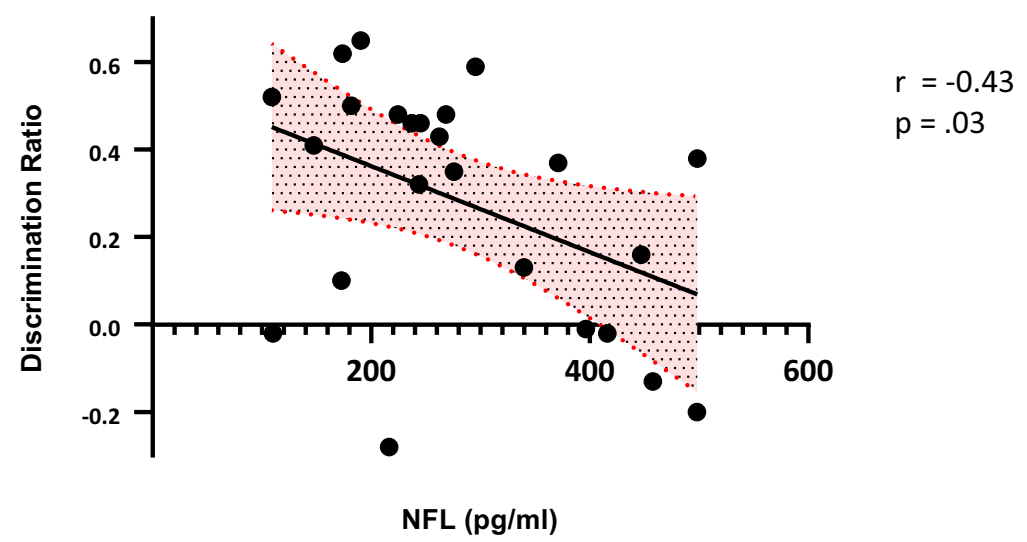

Fig. 4 Treatment with Ang-(1-7)/Mas R agonists decreases plasma NfL levels. A Data are represented with mean and \pm SE. Compares NfL levels between control saline and HF-saline mice, $p=0.08$, Welch's $t$-test. This difference did not reach significance. B PNA5 at 50ug/kg and Ang-(1-7) at $50 \mathrm{ug} / \mathrm{kg}$, and $500 \mathrm{ug} / \mathrm{kg}$ significantly reduced NfL plasma concentration in VCID mice compared to HF-saline treated mice, Kruskal-Wallis ANOVA, Dunn's post, $p<0.05$. C NfL plasma levels significantly negatively correlated with Discrimination ratios. Correlation $\mathrm{R}$ values were produced using Pearson's correlation analysis and the fit line was determined using simple linear regression

impairment mice (HF-A500, mean $0.34 \pm$ SE $0.09, n=12$, $p=0.013$; ANOVA, Dunnett's post).

We have previously demonstrated that VCID mice do not demonstrate altered levels of activity or anxiety compared to control mice during the NOR test $[6,7]$. Consistent with our previous publications, Fig. 3B demonstrates that our mouse model of VCID shows no significant difference in total exploration time during the familiarization phase in all groups. These results indicate that in comparison to Control-Saline-treated mice, VCID mice do not demonstrate altered levels of activity or anxiety (Control-Saline, mean 24.80 \pm SE $7.32 n=13$, HF-Saline, mean $15.61 \pm$ SE 1.91, $n=21$, HF-P50, mean 22.32 \pm SE
7.34, $n=13$, HF-A50, $12.26 \pm$ SE $3.59, n=16$, HF-P500, mean, $7.36 \pm$ SE $1.93, n=11$, HF-A500 $8.47 \pm$ SE 2.34, $n=9$; respectively, $p>0.05$, not significant ANOVA).

\section{NfL plasma levels in VCID mice and effects of Ang-(1-7)/ Mas receptor activation}

Levels of NfL were higher in the HF-Saline-treated mice relative to levels in the Control-Saline mice. The mean NfL level in the HF-VCID mice was $381.6 \pm$ SE 30.0, $(n=10)$ as compared to Control-Saline-treated mice at $301.0 \pm$ SE 32.0, $(\mathrm{n}=12)$. Student's t-test resulted in $p=0.08$ and did not reach significance (Fig. 4A). 


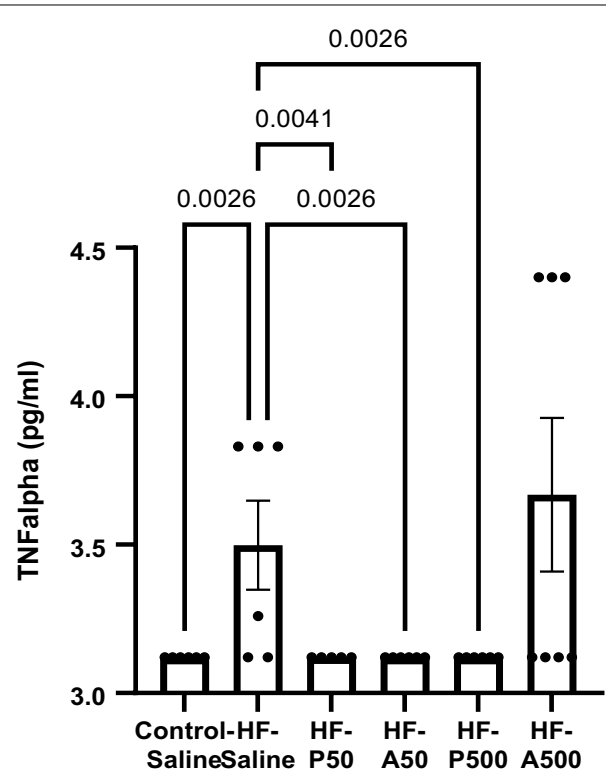

Fig. 5 Increased TNFa in VCID models are inhibited by PNA5 and Ang-(1-7). Plasma TNFa of Control-Saline, HF-Saline, HF-A50 (Ang-(17) $50 \mathrm{ug} / \mathrm{kg}$ ), HF-P50 (PNA5 50ug/kg), HF-A500 (Ang-(1-7)500ug/kg), HF-P500 (PNA5 500ug/kg), were measured via MILLIPLEX MAP Mouse High Sensitivity Multiplex Immunoassay. Significance were observed between HF-Saline vs Control-Saline treated mice (3.50 \pm SE 0.15, $n=6$ vs mean $3.12, \pm$ SE $0.01, n=6$, respectively, $p=0.003 ;)$, PNA5, and Ang-(1-7) (HF-P50 mean $3.12 \mathrm{pg} / \mathrm{mL} \pm$ SE $0.00, n=5 p=0.004$; HF-A50 mean $3.12 \mathrm{pg} / \mathrm{mL} \pm \mathrm{SE} 0.00, n=6, p=0.003 ; \mathrm{HF}-\mathrm{P} 500$ mean $3.12 \mathrm{pg} / \mathrm{mL} \pm$ SE $0.00, n=6, p=0.003$; ANOVA, Dunnett's post; values that were at or below assay threshold of $3.12 \mathrm{pg} / \mathrm{mL}$ were represented as $3.12 \mathrm{pg} / \mathrm{mL}$ )

As illustrated in Fig. 4B, NfL concentrations were significantly lower following treatment with either A50, P50, or A500 as compared to HF-Saline-treated mice (HF-saline, mean $381.6 \pm$ SE 32.0, $(n=12)$, HF-A50, mean $256.7 \pm$ SE $55.8,(n=8), p=0.025$; HF-P50 mean $231.1 \pm$ SE $19.3, \quad(n=6), p=0.025 ;$ HF-A500 mean $149.8 \pm$ SE 23.6, $\quad(n=4), \quad p=0.001 ; \quad$ Kruskal-Wallis ANOVA, Dunn's post).

To assess the relationship between cognitive impairment observed in our VCID model and circulating NfL, NfL levels were correlated to the discrimination ratio score of all mouse groups (Fig. 4C). Plasma NfL was significantly negatively correlated with the discrimination ratio score (Pearson's $r=-0.43, p=0.03$ ), demonstrating that cognitive abilities decrease in this model as neuronal injury markers increase.

\section{Treatment with Ang1-7/MasR agonists affects levels of both brain and circulating cytokines}

Using the MILLIPLEX MAP Mouse High Sensitivity Multiplex Immunoassay, we measured plasma and brain inflammatory profiles after PNA5 and Ang-(1-7) treatments at both the 50 and $500 \mu \mathrm{g} / \mathrm{kilograms} /$ day doses. Among 25 cytokines measured in the plasma, only TNF $\alpha$ exhibited a significant difference between HF-Saline and Control-Saline-treated mice (3.50 $\pm \mathrm{SE}$ $0.15, \mathrm{n}=6$ vs means $3.12 \pm \mathrm{SE} 0.01, \mathrm{n}=6$, respectively, $\mathrm{p}=0.003$; ANOVA, Dunnett's post hoc). PNA5 and Ang-(1-7) inhibited this HF-induced increase in TNF $\alpha$ as compared to HF-saline groups (HF-P50 mean $3.12 \mathrm{pg} / \mathrm{mL} \pm$ SE $0.00, n=5 p=0.004$; HF-A50 mean $3.12 \mathrm{pg} / \mathrm{mL} \pm$ SE $0.00, n=6, p=0.003$; HF-P500 mean $3.12 \mathrm{pg} / \mathrm{mL} \pm \mathrm{SE} 0.00, n=6, p=0.003$, ANOVA, Dunnett's post; values that were at or below assay threshold of $3.12 \mathrm{pg} / \mathrm{mL}$ were represented as $3.12 \mathrm{pg} / \mathrm{mL}$ ) (Fig. 5).

Cytokine levels from brain lysates are summarized in Table 1 and illustrated in Fig. 6. Of the 25 cytokines tested treatments with P50 significantly increased levels of putative-neuroprotective cytokines IL- $1 \alpha$, IL-2, IL-5, IL-13, IL-17, and IP-10, compared to HF-Saline treated mice, ANOVA, Dunnett's post hoc, $p<0.05$ (Fig. 6A-F). Similarly, treatments with A50 or A500 also significantly increased levels of IL-1 $\alpha$, IL-2, IL-5, IL-13, and IL-17 in comparison to HF-Saline-treated mice, ANOVA, Dunnett's post, $\mathrm{p}<0.05$. Lastly, IL-1 $\alpha$, IL-2, IL-17, and IP-10 were significantly decreased in HF-Saline-treated mice in comparison to Control-Saline treated mice (Table 1).

The relationship between levels brain cytokines and NfL was analyzed using Pearson correlation of NfL concentrations and brain cytokines (Table 2, Fig. 7). IL-2, IL-13, IL-17, and the combined cytokine composite score were significantly negatively correlated with NfL plasma concentrations. Figure 8 is a Pearson's correlation matrix illustrating the correlation coefficients between $\mathrm{NfL}$ and those brain cytokines described in Table 2. These data show that (1) NfL is most strongly negatively correlated with the cytokine-composite score and, (2) the levels of IL-2, IL-17 and IL-13 are all strongly positively correlated with each other.

\section{Longitudinal comparisons of circulating inflammatory cytokine and chemokines}

HF is a progressive condition, worsening over time. To highlight the longitudinal impact of HF-induced inflammation, we compared plasma cytokines at 3 weeks postMI, before the onset of HF, to 8 weeks post-MI, when HF has been established (Fig. 9). A significant decrease in IL- $1 \alpha$, MIP- $1 \alpha$, and MIP-2 plasma concentrations was observed in HF-Saline treated mice between the two time periods (Table 3). Unlike IL- $1 \alpha$, and MIP-2, MIP- $1 \alpha$ demonstrated decreased levels 8 weeks post-MI compared to 3 weeks post-MI in both Control-Saline, and HF-Saline treated mice. (IL- $1 \alpha 3$ weeks HF mean $882.3 \mathrm{pg} / \mathrm{mL} \pm \mathrm{SE}$ 198.4, $n=7$ vs 8 week HF mean $209.6 \mathrm{pg} / \mathrm{mL} \pm$ SE 55.7, $\mathrm{n}=6, p=0.0004 ;$ MIP-1 $\alpha 3$ week HF mean 67.9 pg/ 


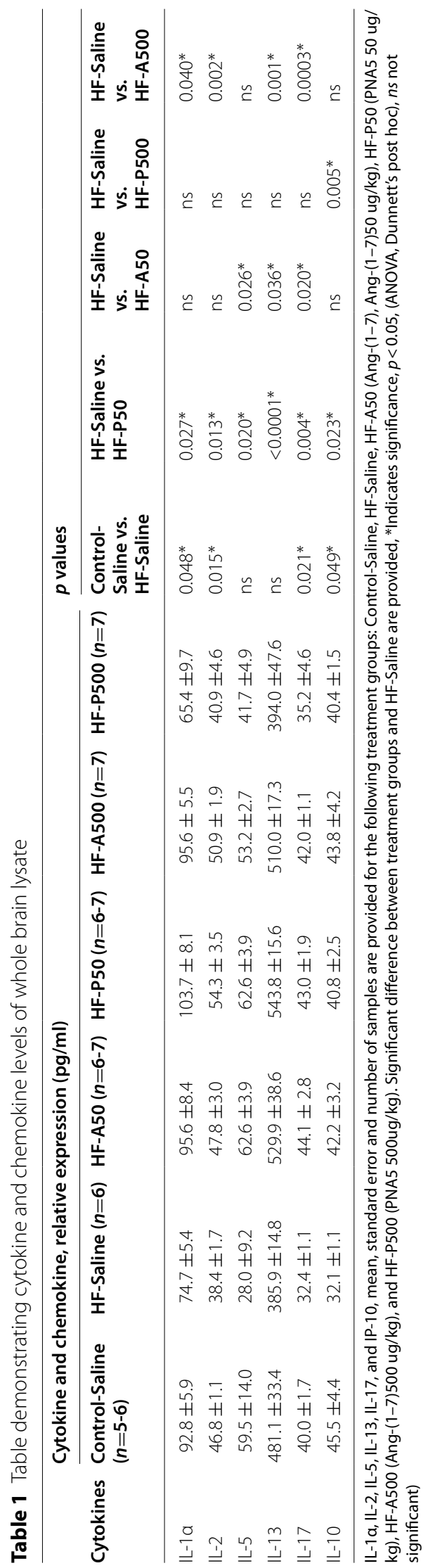




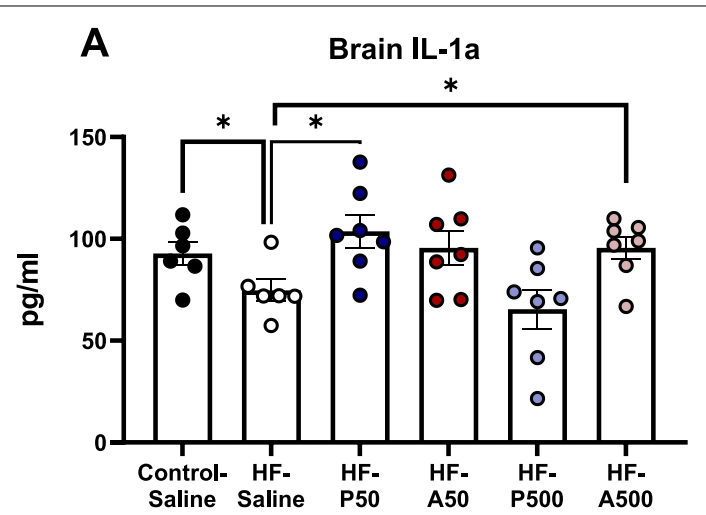

${ }^{*} p<0.05$ HF-Saline vs Control-Saline, HF-P50, HF-A500

C

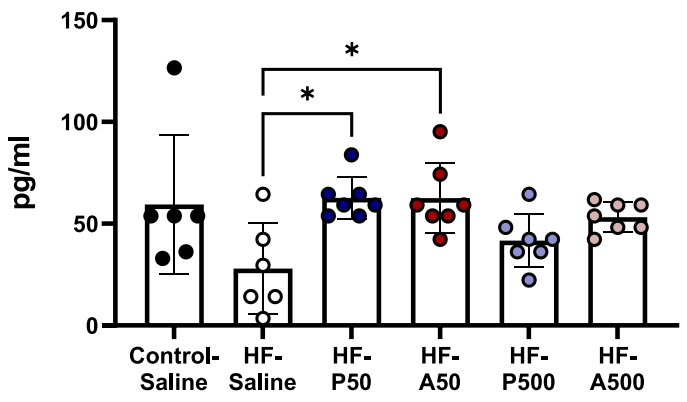

${ }^{*} p<0.05$ HF-Saline vs HF-P50, HF-A50

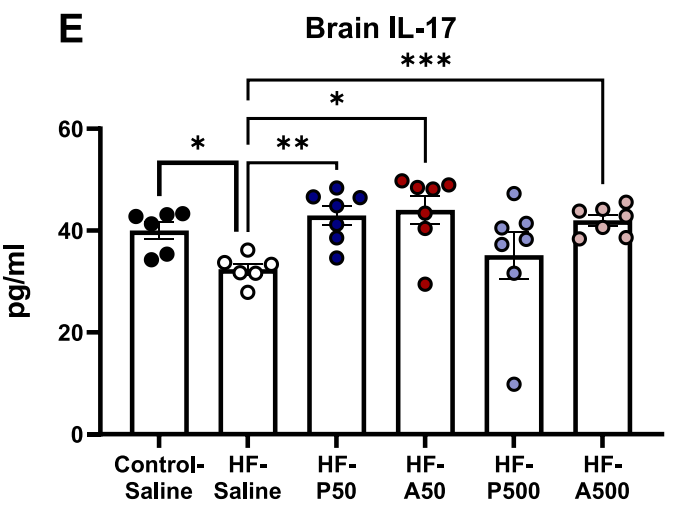

${ }^{*},{ }^{* *},{ }^{* * *} \mathrm{p}<0.05 \mathrm{HF}-$ Saline vs all groups excluding HF-P500
B

Brain IL-2

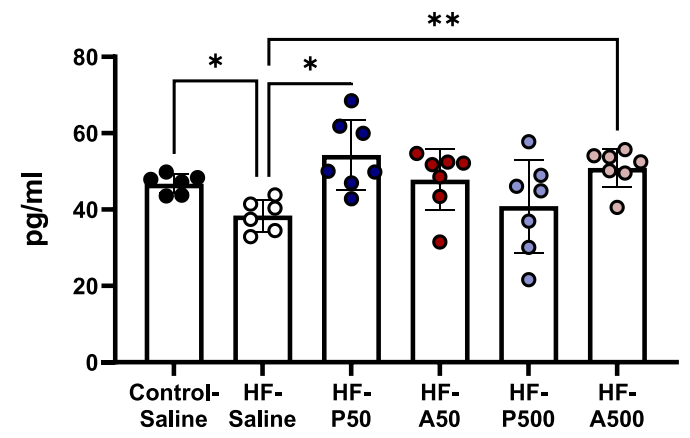

${ }^{*},{ }^{\star *} \mathrm{p}<0.05$ HF-Saline, vs Control-Saline, HF-P50, HF-A500

D Brain IL-13

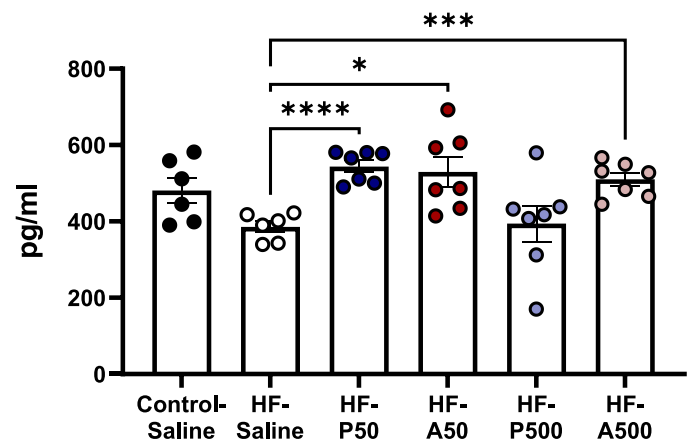

${ }^{*},{ }^{* * *},{ }^{* * * *} p<0.05$ HF-Saline vs HF-P50, HF-A50, HF-A500

$\mathbf{F}$

Brain IP-10

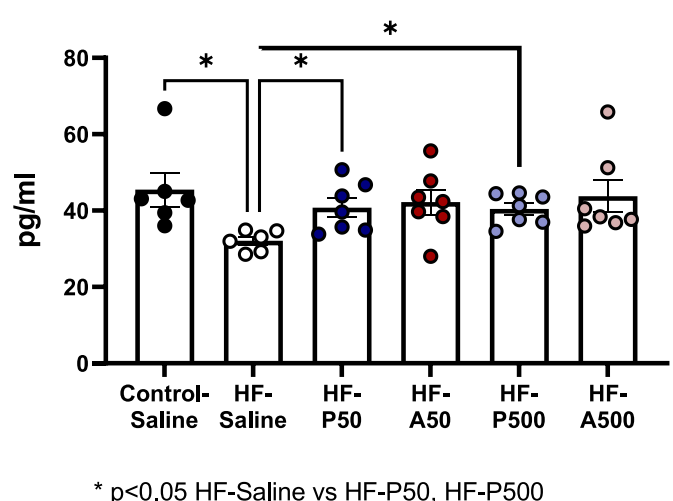

Fig. 6 Effect of treatment with Ang-(1-7)/MasR agonists on brain cytokine levels. Whole brain lysate cytokine levels were measured using MILLIPLEX MAP Mouse High Sensitivity Multiplex Immunoassay. A-F HF-Saline treated VCID mice had significantly lower IL-1 a, IL-2, IL-17, and IP-10 levels in comparison to Control-Saline treated mice. PNA5 and Ang-(1-7) significantly increased cytokines levels as compared to HF-saline treated animals. Data are represented with mean and \pm SE. Differences in groups were tested by ANOVA, Dunnett's post hoc, significance set a $p<0.05$ 
Table 2 NFL vs brain cytokine correlations

\begin{tabular}{lcccrrr}
\hline Cytokines & IL-2 & IL-5 & IL-13 & IP-10 & IL-17 & $\begin{array}{l}\text { Cytokine } \\
\text { composite } \\
\text { Z-score }\end{array}$ \\
\hline rvalue & -0.49 & -0.05 & -0.39 & -0.26 & -0.48 & -0.52 \\
$p$ value & .002 & 0.74 & .013 & 0.11 & .002 & .001 \\
\hline
\end{tabular}

IL-2, IL-5, IL-13, IL-17, IP-10 and the composite cytokine z-score, Pearson's correlation r values and affiliated $p$ values following correlation analysis of NfL levels and cytokine levels in all animal groups are shown. *Indicates significance, $p<0.05$, ns not significant

Table 3 Longitudinal values of HF-induced inflammation comparing plasma cytokines at 3 weeks post-Ml to 8 weeks post-MI

\begin{tabular}{|c|c|c|c|c|c|c|c|}
\hline \multirow[b]{2}{*}{ Cytokines } & \multicolumn{4}{|c|}{ Cytokine and chemokine, relative expression } & \multicolumn{3}{|l|}{$p$ values } \\
\hline & $\begin{array}{l}3 \text { weeks HF } \\
\text { Control-Saline } \\
(n=5)\end{array}$ & $\begin{array}{l}3 \text { weeks HF } \\
\text { HF-Saline }(n=7)\end{array}$ & $\begin{array}{l}8 \text { weeks HF } \\
\text { Control-Saline } \\
(n=6)\end{array}$ & $\begin{array}{l}8 \text { weeks HF } \\
\text { HF-Saline }(n=6)\end{array}$ & $\begin{array}{l}3 \text { weeks } \\
\text { Control-Saline } \\
\text { vs. } 3 \text { weeks } \\
\text { HF-Saline }\end{array}$ & $\begin{array}{l}3 \text { weeks } \\
\text { Control-Saline } \\
\text { vs. } 3 \text { weeks } \\
\text { HF-Saline }\end{array}$ & $\begin{array}{l}3 \text { weeks HF-Saline } \\
\text { vs. } 8 \text { weeks } \\
\text { HF-Saline }\end{array}$ \\
\hline $\mid L-1 a$ & $176.1 \pm 34.8$ & $882.3 \pm 198.4$ & $92.8 \pm 5.9$ & $74.7 \pm 5.4$ & $0.003^{*}$ & 0.964 & $0.0004^{*}$ \\
\hline MIP-1a & $32.6 \pm 9.7$ & $67.9 \pm 6.6$ & $6.8 \pm 1.2$ & $6.4 \pm 1.3$ & $0.002^{*}$ & $0.027^{*}$ & $<0.0001^{*}$ \\
\hline MIP-2 & $65.0 \pm 11.4$ & $155.9 \pm 17.0$ & $45.2 \pm 6.3$ & $54.1 \pm 14.7$ & $0.0009^{*}$ & 0.764 & $0.0001^{*}$ \\
\hline
\end{tabular}

Mean, Standard error, and number of sample values of plasma IL-1a, MIP-1a, and MIP-2 from 3 and 8 weeks post-MI are represented for both treatment groups Control-Saline, and HF-Saline. $P$ values of the following comparison are provided: 3 weeks post-MI Control-Saline and 3 weeks post-MI HF-Saline, 3 weeks post-MI Control-Saline and 8 weeks post-MI Control-Saline, and 3 weeks post-MI HF-Saline and 8 weeks post-MI HF-Saline. *Indicates significance, $p<0.05$, (ANOVA, Tukey's post), ns not significant

$\mathrm{mL} \pm \mathrm{SE} 6.6, n=7$ vs 8 week HF mean $6.4 \mathrm{pg} / \mathrm{mL} \pm \mathrm{SE}$ 1.3, $n=6, p<0.0001$; MIP-2 3 weeks HF mean 155.9 pg/ $\mathrm{mL} \pm \mathrm{SE} 17.0, n=7$ vs 8 weeks HF mean $54.1 \mathrm{pg} / \mathrm{mL} \pm \mathrm{SE}$ 14.7, $n=6, p=0.0001$; ANOVA, Tukey's post).

\section{Discussion}

Vascular contributions to cognitive impairment and dementia (VCID) and Alzheimer's disease-related dementias (ADRD) significantly contribute to the 47 million people world-wide who suffer with dementia. This number is estimated to increase to over 130 million people by 2050. A number of studies have shown that VCID and conversion to ADRD are strongly correlated with vascular disease, inflammation and decreased cerebral brain blood flow [21-28]. The relationship between vascular disease, cognitive function and progression to dementia and possible AD have been recently reviewed [4, 29, 30]. These authors successfully make the case for a close relationship between cardiovascular risk factors and risk for VCID and ADRD. Furthermore, conversion rates of VCID to dementia has been reported to be within $40-46 \%$ within 5 years of diagnosis of VCID [31, 32]. There is an urgent unmet medical need for therapeutics to prevent cognitive decline in individuals at risk for VCID.
In this study, we demonstrate that treatment of our VCID mice with Ang-(1-7)/MasR agonists reverse cognitive dysfunction and decrease circulating NfL as compared to HF-saline-treated animals. This change in NfL level is significantly negatively correlated with cognitive function. These early preclinical data suggest that NfL levels might serve as a prognostic to identify changes in cognitive function in VCID. In addition, NfL significantly correlated with treatment induced changes in brain cytokines further suggesting that NfL may potentially also serve as a pharmacodynamic/ response biomarker for therapeutic target engagement and disease modification. Extensive studies on levels of NfL in humans with VCID are needed to confirm the utility and reliability of NfL as a biomarker for cognitive impairment in individuals at risk for VCID.

\section{$\mathrm{NfL}$ as a biomarker in neurodegenerative diseases}

$\mathrm{NfL}$ is released into the CSF and blood upon axonal damage [10]. Increases in CSF and blood concentrations of NfL have been found in multiple neurodegenerative diseases [33] as well as traumatic brain injury [14], hypoxic brain injury [16], and cardiac disease [17]. Blood NfL levels have been proposed as a biomarker of cognitive decline in Alzheimer's disease (AD) and Parkinson's disease (PD) patients [33, 34. It has been demonstrated that patients experiencing mild 


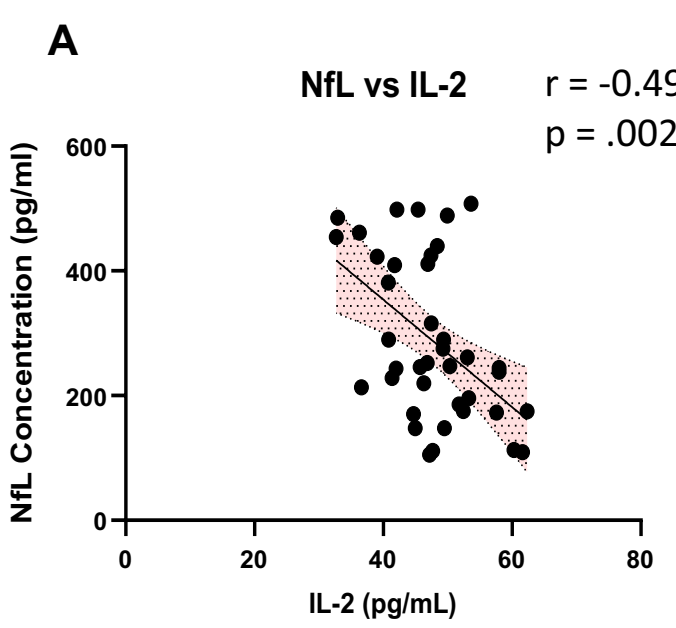

C

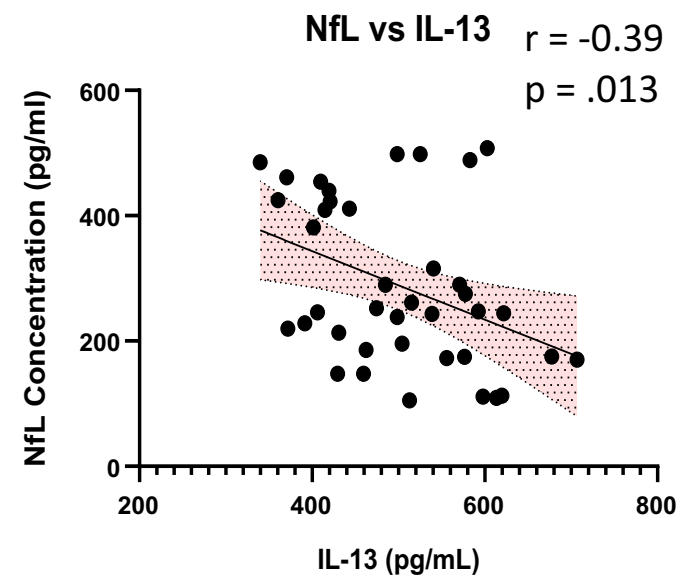

E

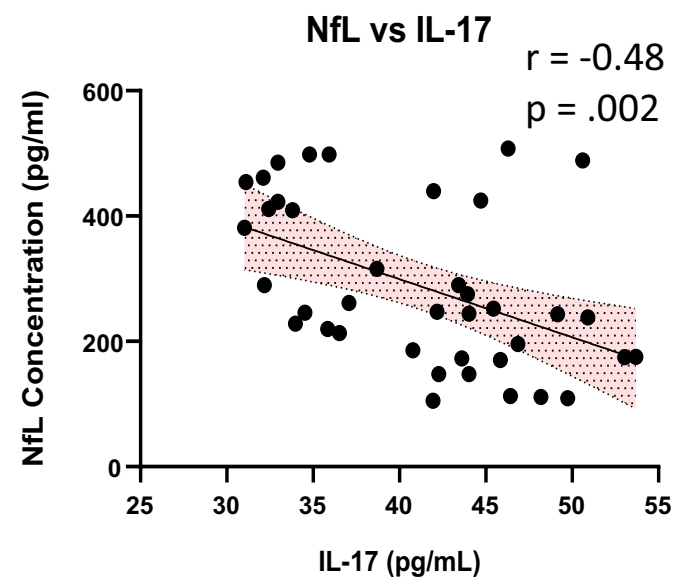

B

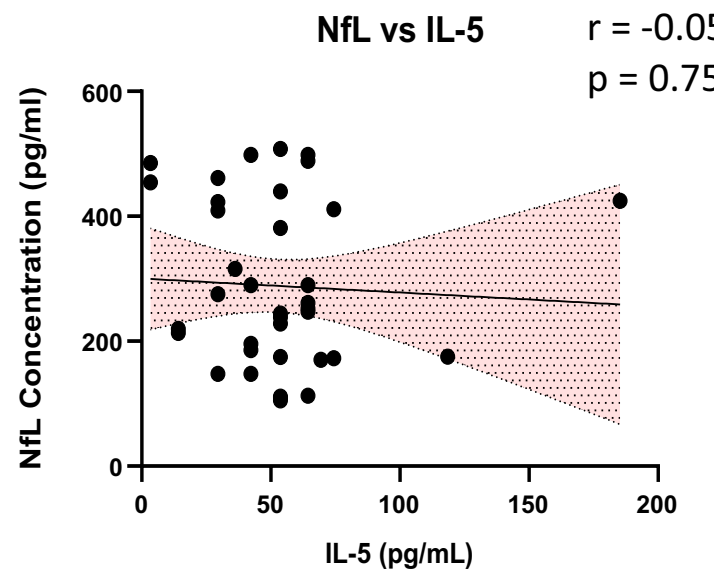

D

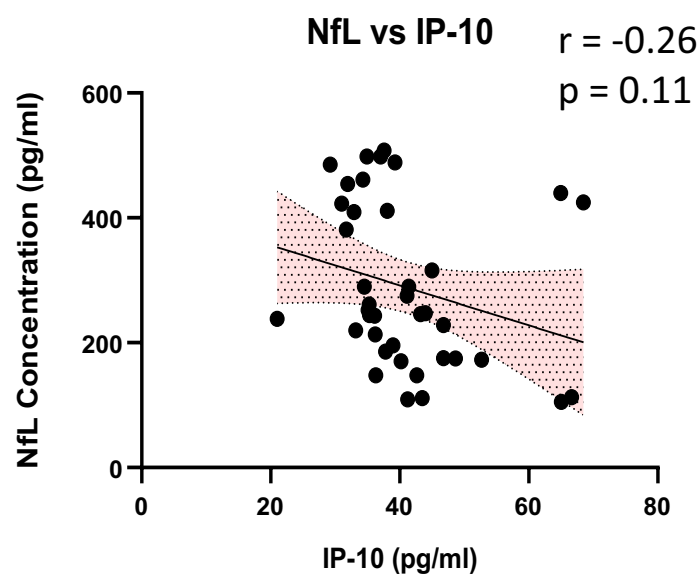

$\mathbf{F}$

NfL Brain Cytokine Composit Score

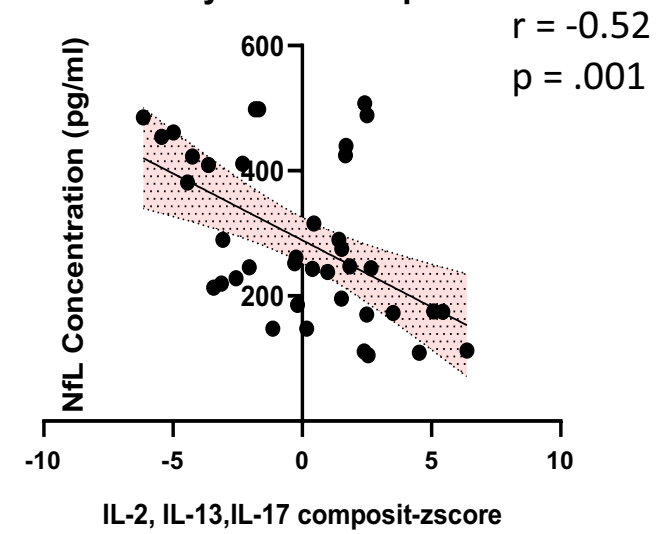

Fig. 7 Relationship between brain cytokine levels and NfL levels. A-E The relationship between brain cytokines IL-2, IL-5, IL-13, IL-17, IP-10, and plasma NfL levels were analyzed using Pearson correlation. F Brain cytokine composite score of IL-2, IL-13, IL-17 were significantly negatively correlated with NfL plasma concentrations 


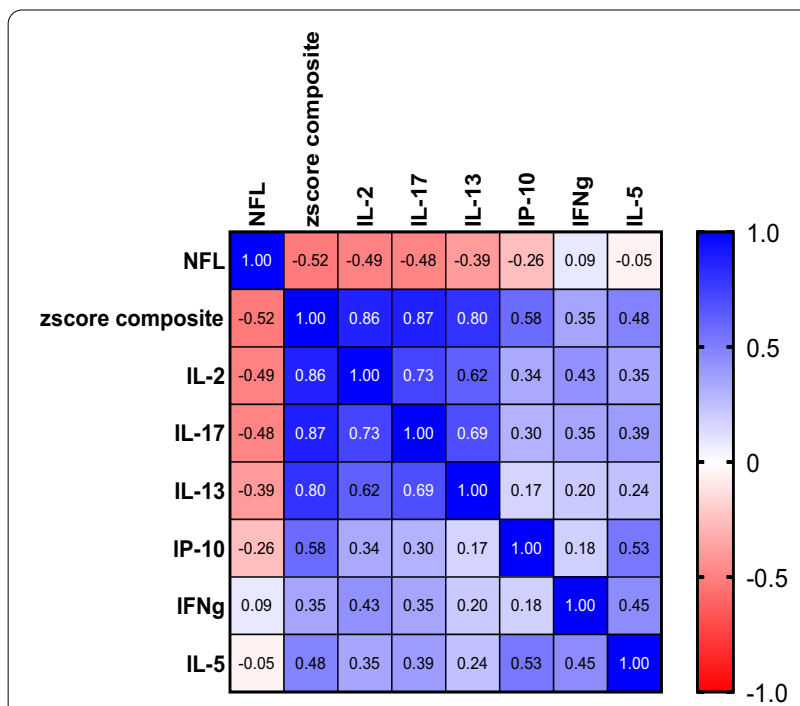

Fig. 8 Pearson's correlation matrix of the relationship between plasma NfL and brain cytokine levels. The relationship between the brain cytokines IL-2, IL-5, IL-13, IL-17, IP-10, the composite cytokine $z$-score and plasma NfL levels were analyzed using Pearson correlation. Blue demonstrates positive correlation and red represents negative correlation. Values closer to 1 or -1 indicate more closely correlated variables

cognitive impairment and dementia stages of $\mathrm{AD}$ have increased blood and CSF NfL levels [35], from these results it has been previously proposed that NfL may be able to help predict the progression of AD dementia in patients [33, 34].

Additionally, it has been demonstrated that CSF NfL levels are increased in patients with vascular dementia $[36,37]$ and that increased NfL levels are correlated to lower MMSE scores [37]. Further, it has been shown that patients with vascular dementia demonstrate a correlation between increased NfL serum levels and decreased cognitive impairment [38]. Studies including CADASIL (a genetic disorder affecting the small blood vessels in the brain), and small vessel disease (SVD) VCID patients also demonstrated increases of NfL correlated to worsened processing speed [39]. In the present study, we provide preclinical support for the hypothesis that NfL may be a prognostic biomarker, as described by the FDA BEST Biomarker Working Group [40] for the identification of cognitive impairment in individuals at risk for VCID.

In the present study we have also shown that treatment with Ang-(1-7)/MasR agonists can decrease $\mathrm{NfL}$ concentrations in our VCID model as compared to HF-saline treated animals and this decrease in NfL is inversely correlated to several pleiotropic cytokines found in the VCID mouse brain. The correlation of blood NfL levels with neurodegenerative treatment protocols has been demonstrated in previous human studies. In MS patients, studies have shown that blood levels of NfL correlate with MS related disability and can predict the longitudinal course of the disease as well as response to treatment [41-43].

\section{Systemic and brain inflammation}

A number of different mechanisms have been suggested to contribute to VCID $[44,45]$. Systemic inflammation has been linked to impaired cognitive function [46, 47]. Specifically circulating TNF $\alpha$ is increased in HF patients $[48,49]$ and has been demonstrated to contribute to pathologic cognitive changes [47]. In this study we observed that TNF $\alpha$ was significantly increased in the HF-Saline treated mice compared to the ControlSaline treated mice, thereby possibly contributing to systemic inflammation in our VCID mouse model. Importantly, treatment with Ang-(1-7)/MasR agonists in VCID mice reversed not only cognitive impairment, but also decreased NfL levels, and systemic TNF $\alpha$ concentrations. These data provide further evidence that NfL might serve as a biomarker to indicate target engagement of the disease-modifying treatment with our Ang-(1-7)/MasR agonists.

We have also begun to identify longitudinal changes in circulating inflammatory cytokine profiles in our VCID mouse model. We compared changes in systemic cytokines in animals with 3 weeks of HF to animals with 8 weeks of HF. Previously, we have identified inflammatory biomarkers associated with the early progression of VCID following the onset of HF (3 weeks following MI) [6]. IL-1 $\alpha$, MIP-1 $\alpha$, MIP-2, and GCSF in HF-Saline mice were significantly increased compared to the Control-Saline treated mice 3 weeks following MI [6]. These data reveal a longitudinal decrease in IL- $1 \alpha$, MIP- $1 \alpha$, and MIP- 2 which provides insight into the inflammatory mechanism of VCID development.

Regarding brain cytokines, HF-Saline treated mice had decreased levels of IL-1 $\alpha$ IL-2, IL-17, and IP-10 in comparison to Control-Saline treated mice. Treatment with P50 significantly increased IL-1 $\alpha$, IL-2, IL-5, IL-13, IL-17 and IP-10 levels, and treatments with Ang-(1-7) also significantly increased levels of IL- $1 \alpha$, IL-2, IL-5, IL-13, and IL-17 in comparison to HF-Saline treated mice.

IL- $1 \alpha$ has been shown to have brain protective qualities in mouse stroke models and promotes neurorepair when mice are treated with delayed administration of IL- $1 \alpha$ [50]. Other studies have demonstrated that IL- $1 \alpha$ induces angiogenesis in brain endothelial cells in vitro [51]. Further it was observed that IL- $1 \alpha$ levels increase within the brain in post-stroke animal models during angiogenic periods [51]. In the current study IL-1 $\alpha$ was significantly 

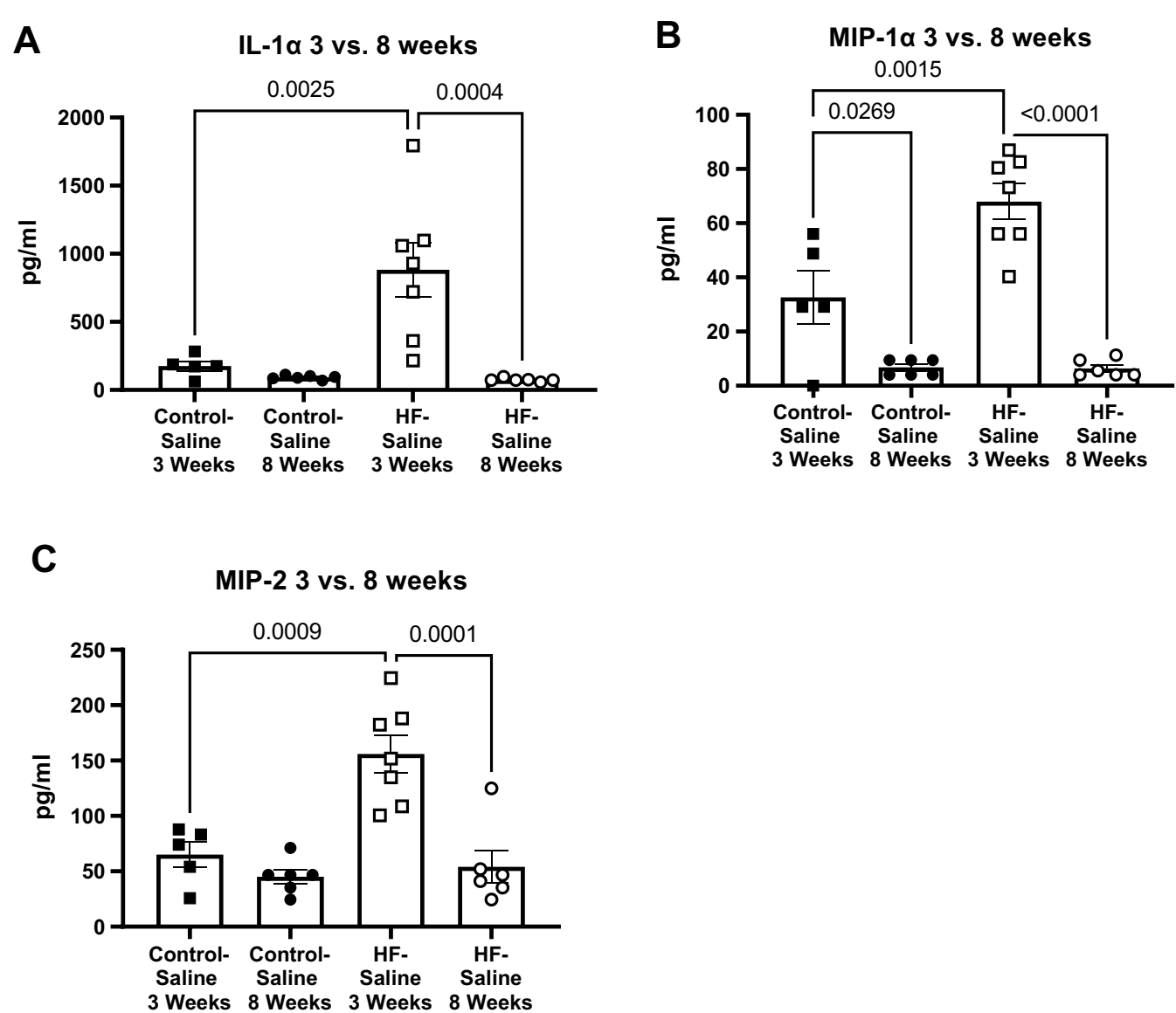

Fig. 9 Longitudinal comparison of plasma cytokines in VCID mouse model. A-C Plasma inflammatory cytokine levels from mice with 3 weeks of HF, and 8 weeks of HF, in both Control-Saline, and HF-Saline treated mice were measured via MILLIPLEX MAP Mouse High Sensitivity Multiplex Immunoassay. At 3 weeks of HF, HF-Saline mice had significantly higher IL-1a, MIP-1a, and MIP-2 concentrations than age-matched Control-Saline treated mice. A significant decrease in cytokine concentrations was observed in HF-Saline-treated mice from 3 to 8 weeks of HF. Data are represented with mean and \pm SE. Difference in groups were tested by ANOVA

lower in HF-Saline treated mice compared to ControlSaline treated mice, and that treatment of P50, or A500 increases IL- $1 \alpha$ significantly in comparison to HF-Saline mice. Suggesting that treatment with Ang-(1-7)/MasR agonists may provide brain protection and neurorepair by increasing brain IL- $1 \alpha$ levels.

IL-2 has also been shown to play a protective role in the brain. IL-2 has been shown to decrease amyloid plaque load, improve synaptic plasticity, and has been associated with memory recovery in AD mice [52]. We observed that IL-2 brain levels significantly decreased in our VCID model in comparison to controls. We further demonstrated that treatment with P50, or A500 significantly increased IL-2 levels in comparison to HF-Saline mice, and that IL-2 levels were significantly negatively correlated with NfL levels. These data suggest that one of the mechanisms by which Ang-(1-7)/MasR treatment protects cognitive function may include increasing IL-2.
IL-5 is a Th2 cytokine that can act as an immunosuppressor [53] and contributes to maintaining homogeneity of astrocyte activation states [54]. Elevated serum levels of IL- 5 have been have been reported in both VCID patients and vascular encephalopathy (VE) [53]. It has been suggested that elevated levels of IL-5 in VCID and VE may contribute to disease reduction. In PC12 cells, treatments of IL- 5 decreased neuronal cell apoptosis, and $\mathrm{A} \beta_{25-35}$ induced tau phosphorylation [54]. In the present study we show that treatments with P50, or A50 significantly increase brain IL-5 levels compared to HF-Saline mice. These data suggest that elevated IL-5 levels may contribute to the mechanism by which Ang-(1-7)/MasR treatment protects cognitive function.

IL-13 has been shown to play both a protective and injurious role in the brain. While IL-13 has been demonstrated to be neuroprotective by modulating microglia/ macrophage responses in traumatic brain injury [55], 
other studies have shown that IL-13 can be detrimental to neuronal survival [56]. Here we found that treatment with P50, A50, and A500 significantly increase IL-13 levels in comparison to HF-Saline treated mice. The IL-13 levels were significantly negatively correlated to NfL plasma concentrations. These data indicate that IL-13 may play a neuroprotective role following treatment with Ang-(1-7)/MasR agonists in our mouse model of VCID.

IL-17 has also been shown to play both a protective and injurious role in the brain. Although IL-17 is typically linked to proinflammatory disease progression [57], it has also been shown to promote tissue repair via meningeal resident gamma delta T-cells and support long-term potentiation (LTP) and the plasticity of glutamatergic synapses during short-term learning [58]. We observed that HF-Saline treated mice had significantly lower levels of IL-17 than Control-Saline treated mice, and that treatments with P50, A50, or A500 normalized IL-17 brain concentrations. Further, levels of IL-17 were significantly negatively correlated with $\mathrm{Nfl}$ levels. These findings suggest that Ang-(1-7)/MasR agonists increase IL-17 levels in VCID mice, which may contribute to these peptides' cognitive protective effects.

IP-10 (CXCL-10) has been demonstrated to increase in the pathogenesis of $\mathrm{AD}$ [59]. In contrast, studies with $\mathrm{AD}$ patients demonstrate an increased in CSF and plasma IP-10 levels were independently associated with NfL levels [60]. In our model of VCID, we observed IP-10 brain levels were significantly higher in both Control-Salinetreated mice and Ang-(1-7)/MasR agonist-treated HF mice as compared to HF-Saline mice.

In total, these data suggest that in our VCID model there is a decrease in the levels of multiple pleiotropic cytokines in HF-saline-treated animals. Treatment with Ang-(1-7)/MasR agonists mitigated cognitive impairment in this model while simultaneously increasing the levels of these pleotropic, and some putative neuroprotective cytokines, some of which are correlated to decreases blood NfL levels.

Finally, while extensive human studies are needed to support this premise, we propose that NfL may be a potential predictive biomarker to identify individuals who are at risk for VCID and pharmacodynamic biomarker to indicate target engagement following Ang-(17)/MasR therapy to protect cognitive function.

\section{Study limitations}

One limitation of this study is the lack of data in female animals. We appreciate that effects of both HF and drug treatment may be different in female animals, and we have plans to fully investigate the effects of HF and Ang-(1-7)/MasR treatments in female mice in future studies. A second limitation of this study, is the lack of complete longitudinal data showing the change in circulating and brain cytokines over the course of development of the HF post-MI. While our results comparing 3-week to 8-week post-MI levels of cytokines in both plasma and brain suggest that the levels of these cytokines do change during disease progression a more extensive analysis of the time-course of these changes and the time-course of the effectiveness of treatment with Ang-(1-7)/MasR therapies will be needed to better understand the inflammatory mechanisms underlying the development of VCID.

\section{Abbreviations}

Ang-(1-7): Angiotensin 1-7; A50: Ang-(1-7) at 50ug/kg; A500: Ang-(1-7) at 500ug/kg; ADRD: Alzheimer disease-related dementia; Echo: Echocardiograph; EF: Ejection fraction; ESV: End systolic volume; HF: Heart failure; NfL: Neurofilament light; MI: Myocardial infarct; P50: PNA5 at 50ug/kg; P500: PNA5 at 500ug/kg; ROS: Reactive oxidative species; SVD: Small vessel disease; VaD: Vascular dementia; VCID: Vascular contributions to cognitive impairment and dementia; VE: Vascular encephalopathy.

\section{Acknowledgements}

The authors would like to thank Joshua Strom, PhD. for performing the myocardial infarct surgeries and echocardiographs. We would also like to also thank Joshua P. Fricks, BSN. Victoria E. Salcedo, BS. and Nova E Wilson for their contributions to tissue processing, staining, and aid in animal experiments.

\section{Authors' contributions}

The author contributed to the lab work, analysis and interpretation of data, and writing included in the current manuscript. All authors read and approved the final manuscript.

\section{Funding \\ NIA U01AG066623-01.}

\section{Declarations}

Ethics approval and consent to participate

All procedures, handling, and treatments were approved by the institutional Animal Care and Use Committee at the University of Arizona in agreement with the National Institute of Health Guidelines for the care and Use of Laboratory Animals.

\section{Consent for publication \\ Not applicable.}

\section{Competing interests}

COI, Dr. Meredith Hay is the founder of ProNeurogen, Inc. that holds exclusive rights to the clinical development of the Ang-(1-7)/MasR agonists described herein.

\footnotetext{
Author details

${ }^{1}$ Department of Physiology, The University of Arizona, Tucson, AZ, USA ${ }^{2}$ Department of Nutritional Sciences, The University of Arizona, Tucson, AZ, USA. ${ }^{3}$ Department of Biomedical Engineering, The University of Arizona, Tucson, AZ, USA. ${ }^{4}$ Sarver Molecular Cardiovascular Research Program, The University of Arizona, Tucson, AZ, USA. ${ }^{5}$ Department of Pharmacy, Skaggs Pharmaceutical Sciences Center, The University of Arizona, Tucson, AZ, USA. ${ }^{6}$ Department of Medicine, Division of Translational and Regenerative Medicine, The University of Arizona, Tucson, AZ, USA. 'D Department of Chemistry and Biochemistry, The University of Arizona, Tucson, AZ, USA. ${ }^{8}$ Department of Immunobiology, The University of Arizona, Tucson, AZ, USA. ${ }^{9}$ Department of Neurology, The University of Arizona, Tucson, AZ, USA. ${ }^{10}$ Evelyn F. McKnight Brain Institute, The University of Arizona, Tucson, AZ, USA. ${ }^{11}$ Department
} 
of Epidemiology and Biostatistics, The University of Arizona, Tucson, AZ, USA.

${ }^{12}$ ProNeurogen, Inc, The University of Arizona, Tucson, AZ, USA.

Received: 29 March 2021 Accepted: 20 September 2021

Published online: 15 October 2021

\section{References}

1. Qiu C, Winblad B, Marengoni A, Klarin I, Fastbom J, Fratiglioni L. Heart failure and risk of dementia and Alzheimer disease: A population-based cohort study. Arch Intern Med. 2006;166(9):1003-8.

2. Audia C, Santos Y, Snyder PJ, Wu W-C, Zhang M, Echeverria A, et al. Pathophysiologic relationship between Alzheimer's disease, cerebrovascular disease, and cardiovascular risk: a review and synthesis. Alzheimers Dement. 2017. https://doi.org/10.1016/j.dadm.2017.01.005.

3. Corriveau RA, Bosetti F, Emr M, Gladman JT, Koenig Jl, Moy CS, et al. The science of vascular contributions to cognitive impairment and dementia (vcid): a framework for advancing research priorities in the cerebrovascular biology of cognitive decline. Cell Mol Neurobiol. 2016;36:281-8.

4. Mp M, Ra C, Dm W. Vascular contributions to cognitive impairment and dementia (VCID). Biochim Biophys Acta. 2016;1862(5):857-9.

5. Rodgers KE, Oliver J, DiZerega GS. Phase I/II dose escalation study of angiotensin 1-7 [A(1-7)] administered before and after chemotherapy in patients with newly diagnosed breast cancer. Cancer Chemother Pharmacol. 2006;57(5):559-68.

6. Hay M, Vanderah TW, Samareh-Jahani F, Constantopoulos E, Uprety AR, Barnes CA, et al. Cognitive impairment in heart failure: a protective role for angiotensin-(1-7). Behav Neurosci. 2017;131(1):99-114.

7. Hay M, Polt R, Heien ML, Vanderah TW, Largent-Milnes TM, Rodgers $K$, et al. A novel angiotensin-(1-7) glycosylated mas receptor agonist for treating vascular cognitive impairment and inflammation-related memory dysfunction. J Pharmacol Exp Ther. 2019;369:9-25.

8. Jiang T, Yu JT, Zhu XC, Zhang QQ, Tan MS, Cao L, et al. Angiotensin-(1-7) induces cerebral ischaemic tolerance by promoting brain angiogenesis in a Mas/eNOS-dependent pathway. Br J Pharmacol. 2014;171(18):4222-32.

9. Ferrario $\mathrm{CM}$. Angiotensin-converting enzyme 2 and angiotensin-(1-7): an evolving story in cardiovascular regulation. Hypertension. 2006. https:// doi.org/10.1161/01.HYP.0000196268.08909.fb.

10. Zetterberg H. Neurofilament light: a dynamic cross-disease fluid biomarker for neurodegeneration. Neuron. 2016. https://doi.org/10.1016/j. neuron.2016.06.030

11. Ashton NJ, Leuzy A, Lim YM, Troakes C, Hortobágyi T, Höglund K, et al. Increased plasma neurofilament light chain concentration correlates with severity of post-mortem neurofibrillary tangle pathology and neurodegeneration. Acta Neuropathol Commun. 2019;7(1):5.

12. Gaetani L, Salvadori N, Lisetti V, Eusebi P, Mancini A, Gentili L, et al. Cerebrospinal fluid neurofilament light chain tracks cognitive impairment in multiple sclerosis. J Neurol. 2019;266(9):2157-63.

13. Villar LM, Picón C, Costa-Frossard L, Alenda R, García-Caldentey J, Espiño $M$, et al. Cerebrospinal fluid immunological biomarkers associated with axonal damage in multiple sclerosis. Eur J Neurol. 2015;22(8):1169-75.

14. Thelin $\mathrm{E}$, Al Nimer F, Frostell A, Zetterberg H, Blennow K, Nyström $H$, et al. A Serum protein biomarker panel improves outcome prediction in human traumatic brain injury. J Neurotrauma. 2019;36(20):2850-62.

15. Shahim P, Politis A, van der Merwe A, Moore B, Chou YY, Pham DL, et al. Neurofilament light as a biomarker in traumatic brain injury. Neurology. 2020;95(6):e610-22.

16. Nielsen HH, Soares CB, Høgedal SS, Madsen JS, Hansen RB, Christensen $A A$, et al. Acute neurofilament light chain plasma levels correlate with stroke severity and clinical outcome in ischemic stroke patients. Front Neurol. 2020;11:11.

17. Wiberg S, Holmgaard F, Blennow K, Nilsson JC, Kjaergaard J, Wanscher $M$, et al. Associations between mean arterial pressure during cardiopulmonary bypass and biomarkers of cerebral injury in patients undergoing cardiac surgery: secondary results from a randomized controlled trial. Interact Cardiovasc Thorac Surg. 2020. https://doi.org/10.1093/icvts/ivaa2 64.

18. Gao XM, Dart AM, Dewar E, Jennings G, Du XJ. Serial echocardiographic assessment of left ventricular dimensions and function after myocardial infarction in mice. Cardiovasc Res. 2000;45(2):330-8.
19. Ennaceur A, Delacour J. A new one-trial test for neurobiological studies of memory in rats. 1: Behavioral data. Behav Brain Res. 1988;31 (1):47-59.

20. Rumberger JA. Ventricular dilatation and remodeling after myocardial infarction. Mayo Clinic Proc. 1994. https://doi.org/10.1016/S00256196(12)61345-7.

21. Kapasi A, Schneider JA. Vascular contributions to cognitive impairment, clinical Alzheimer's disease, and dementia in older persons. Biochim Biophys Acta Mol Basis Dis. 2016;1862(5):878-86.

22. Toledo JB, Toledo E, Weiner MW, Jack CR, Jagust W, Lee VMY, et al. Cardiovascular risk factors, cortisol, and amyloid- $\beta$ deposition in Alzheimer's Disease Neuroimaging Initiative. Alzheimer's Dement. 2012;8(6):483-9.

23. Yarchoan M, Xie SX, Kling MA, Toledo JB, Wolk DA, Lee EB, et al. Cerebrovascular atherosclerosis correlates with Alzheimer pathology in neurodegenerative dementias. Brain. 2012;135(12):3749-56.

24. van Oijen M, de Jong FJ, Witteman JCM, Hofman A, Koudstaal PJ, Breteler MMB. Atherosclerosis and risk for dementia. Ann Neurol. 2007:61(5):403-10.

25. Gorelick PB, Furie KL, ladecola C, Smith EE, Waddy SP, Lloyd-Jones DM, et al. Defining optimal brain health in adults: a presidential advisory from the American Heart Association/American Stroke Association. Stroke. 2017:48(10):e284-303.

26. Santos CY, Snyder PJ, Wu W-C, Zhang M, Echeverria A, Alber J. Pathophysiologic relationship between Alzheimer's disease, cerebrovascular disease, and cardiovascular risk: a review and synthesis. Alzheimers Dement. 2017;7(1):69-87.

27. Canobbio I, Abubaker AA, Visconte C, Torti M, Pula G. Role of amyloid peptides in vascular dysfunction and platelet dysregulation in Alzheimer's disease. Front Cell Neurosci. 2015. https://doi.org/10.3389/fncel. 2015.00065.

28. Janota C, Lemere CA, Brito MA. Dissecting the Contribution of Vascular Alterations and Aging to Alzheimer's Disease. Mol Neurobiol. 2015;53(6):3793-811.

29. Sweeney MD, Montagne A, Sagare AP, Nation DA, Schneider LS, Chui $\mathrm{HC}$, et al. Vascular dysfunction - the disregarded partner of Alzheimer's disease. Alzheimer's Dement. 2019;15(1):158-67.

30. Helman AM, Murphy MP. Vascular cognitive impairment: Modeling a critical neurologic disease in vitro and in vivo. Biochim Biophys Acta Mol Basis Dis. 2016;1862(5):975-82.

31. Wentzel C, Rockwood K, MacKnight C, Hachinski V, Hogan DB, Feldman $H$, et al. Progression of impairment in patients with vascular cognitive impairment without dementia. Neurology. 2001;57(4):714-6.

32. Hsiung GYR, Donald A, Grand J, Black SE, Bouchard RW, Gauthier SG, et al. Outcomes of cognitively impaired not demented at 2 years in the Canadian cohort study of cognitive impairment and related dementias. Dement Geriatr Cogn Disord. 2006;22(5-6):413-20.

33. Mattsson $N$, Andreasson U, Zetterberg $H$, Blennow K, Weiner MW, Aisen $P_{t}$ et al. Association of plasma neurofilament light with neurodegeneration in patients with Alzheimer disease. JAMA Neurol. 2017;74(5):557-66.

34. Olsson B, Lautner R, Andreasson U, Öhrfelt A, Portelius E, Bjerke M, et al. CSF and blood biomarkers for the diagnosis of Alzheimer's disease: a systematic review and meta-analysis. Lancet Neurol. 2016;15(7):673-84.

35. Petzold A, Keir G, Warren J, Fox N, Rossor MN. A systematic review and meta-analysis of CSF neurofilament protein levels as biomarkers in dementia. Neurodegener Dis. 2007;4(2-3):185-94.

36. Rosengren LE, Karlsson JE, Sjögren M, Blennow K, Wallin A. Neurofilament protein levels in CSF are increased in dementia. Neurology. 1999:52(5):1090-3.

37. Skillbäck T, Farahmand B, Bartlett JW, Rosén C, Mattsson N, Nägga K, et al. CSF neurofilament light differs in neurodegenerative diseases and predicts severity and survival. Neurology. 2014;83(21):1945-53.

38. Ma W, Zhang J, Xu J, Feng D, Wang X, Zhang F. Elevated levels of serum neurofilament light chain associated with cognitive impairment in vascular dementia. Dis Markers. 2020. https://doi.org/10.1155/2020/6612871.

39. Cipollini V, Troili F, Giubilei F. Emerging biomarkers in vascular cognitive impairment and dementia: from pathophysiological pathways to clinical application. IJMS. 2019. https://doi.org/10.3390/ijms20112812.

40. FDA-NIH Biomarker Working Group. BEST (Biomarkers, EndpointS, and other Tools). Silver Spring (MD): Food and Drug Administration (US); 2016-. Available from: https://www.ncbi.nlm.nih.gov/books/NBK326791/ Co-published by National Institutes of Health (US), Bethesda (MD). 
41. Kuhle J, Kropshofer H, Haering DA, Kundu U, Meinert R, Barro C, et al. Blood neurofilament light chain as a biomarker of MS disease activity and treatment response. Neurology. 2019;92(10):e1007-15.

42. Kapoor R, Smith KE, Allegretta M, Arnold DL, Carroll W, Comabella M, et al. Serum neurofilament light as a biomarker in progressive multiple sclerosis. Neurology. 2020;95(10):436-44.

43. Varhaug KN, Torkildsen $\varnothing$, Myhr KM, Vedeler CA. Neurofilament light chain as a biomarker in multiple sclerosis. Front Neurol. 2019. https://doi.org/ 10.3389/fneur.2019.00338.

44. Price BR, Norris CM, Sompol P, Wilcock DM. An emerging role of astrocytes in vascular contributions to cognitive impairment and dementia. J Neurochem. 2018;144(5):644-50.

45. Price BR, Wilcock DM, Weekman EM. Hyperhomocysteinemia as a risk factor for vascular contributions to cognitive impairment and dementia. Front Aging Neurosci. 2018;31:350.

46. Trollor JN, Smith E, Agars E, Kuan SA, Baune BT, Campbell L, et al. The association between systemic inflammation and cognitive performance in the elderly: The Sydney Memory and Ageing Study. Age (Omaha). 2012;34(5):1295-308.

47. Bruunsgaard H. A high plasma concentration of TNF-a is associated with dementia in centenarians. J Gerontol Ser A Biol Sci Med Sci. 1999. https:// doi.org/10.1093/gerona/54.7.M357.

48. Yndestad A, Damås JK, Øie E, Yndestad A, et al. Systemic inflammation in heart failure - the whys and wherefores. Hear Fail Rev. 2006;11:83-92.

49. Aukrust $P$, Ueland $T$, Lien E, Bendtzen K, Müller F, Andreassen AK, et al. Cytokine network in congestive heart failure secondary to ischemic or idiopathic dilated cardiomyopathy. Am J Cardiol. 1999;83(3):376-82.

50. Salmeron KE, Maniskas ME, Edwards DN, Wong R, Rajkovic I, Trout A, et al. Interleukin 1 alpha administration is neuroprotective and neurorestorative following experimental ischemic stroke. J Neuroinflammation. 2019;16(1):222

51. Salmeron K, Aihara T, Redondo-Castro E, Pinteaux E, Bix G. IL-1alpha induces angiogenesis in brain endothelial cells in vitro: Implications for brain angiogenesis after acute injury. J Neurochem. 2016;136(3):573-80.
52. Alves S, Churlaud G, Audrain M, Michaelsen-Preusse K, Fol R, Souchet $B$, et al. Interleukin-2 improves amyloid pathology, synaptic failure and memory in Alzheimer's disease mice. Brain. 2017;140(3):826-42.

53. Schmitz M, Hermann P, Oikonomou P, Stoeck K, Ebert E, Poliakova T, et al. Cytokine profiles and the role of cellular prion protein in patients with vascular dementia and vascular encephalopathy. Neurobiol Aging. 2015;36(9):2597-606

54. Zhou Y, Li C, Li D, Zheng Y, Wang J. IL-5 blocks apoptosis and tau hyperphosphorylation induced by A $225-35$ peptide in PC12 cells. J Physiol Biochem. 2017;73(2):259-66.

55. Miao W, Zhao Y, Huang Y, Chen D, Luo C, Su W, et al. IL-13 ameliorates neuroinflammation and promotes functional recovery after traumatic brain injury. J Immunol. 2020;204(6):1486-98.

56. Morrison BE, Marcondes MCG, Nomura DK, Sanchez-Alavez M, SanchezGonzalez A, Saar I, et al. Cutting edge: IL-13Ra1 expression in dopaminergic neurons contributes to their oxidative stress-mediated loss following chronic peripheral treatment with lipopolysaccharide. J Immunol. 2012;189(12):5498-502.

57. Cipollini V, Anrather J, Orzi F, ladecola C. Th17 and cognitive impairment: possible mechanisms of action. Front Neuroanat. 2019. https://doi.org/ 10.3389/fnana.2019.00095.

58. Bordon Y. IL-17: an immune mnemonic. Nat Rev Immunol. 2019. https:// doi.org/10.1038/s41577-019-0237-1.

59. McKimmie C, Michlmayr D. Role of CXCL10 in central nervous system inflammation. Int J Interf Cytokine Mediat Res. 2014;6(1):1.

60. Bettcher BM, Johnson SC, Fitch R, Casaletto KB, Heffernan KS, Asthana S, et al. CSF and plasma levels of inflammation differentially relate to CNS markers of Alzheimer's disease pathology and neuronal damage hhs public access. J Alzheimers Dis. 2018;62(1):385-97.

\section{Publisher's Note}

Springer Nature remains neutral with regard to jurisdictional claims in published maps and institutional affiliations.
Ready to submit your research? Choose BMC and benefit from:

- fast, convenient online submission

- thorough peer review by experienced researchers in your field

- rapid publication on acceptance

- support for research data, including large and complex data types

- gold Open Access which fosters wider collaboration and increased citations

- maximum visibility for your research: over 100M website views per year

At BMC, research is always in progress.

Learn more biomedcentral.com/submissions 